
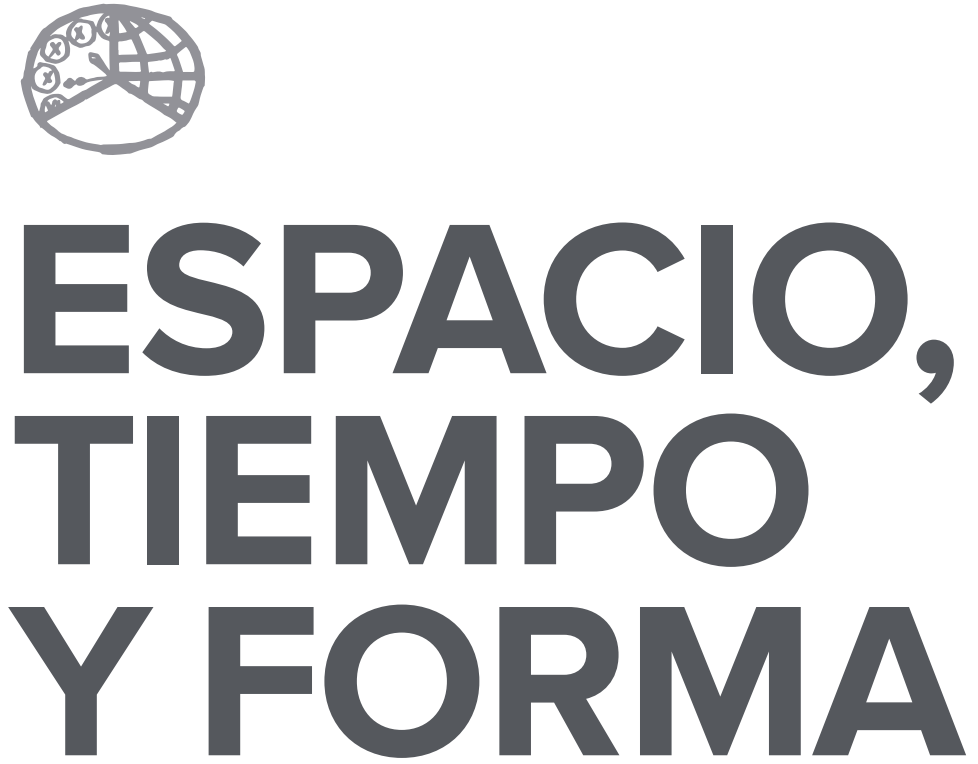

AÑO 2021

ISSN 0214-9745

E-ISSN 2340-1362

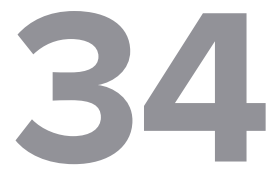

SERIE III HISTORIA MEDIEVAL

REVISTA DE LA FACULTAD DE GEOGRAFÍA E HISTORIA

VOLUMEN I 


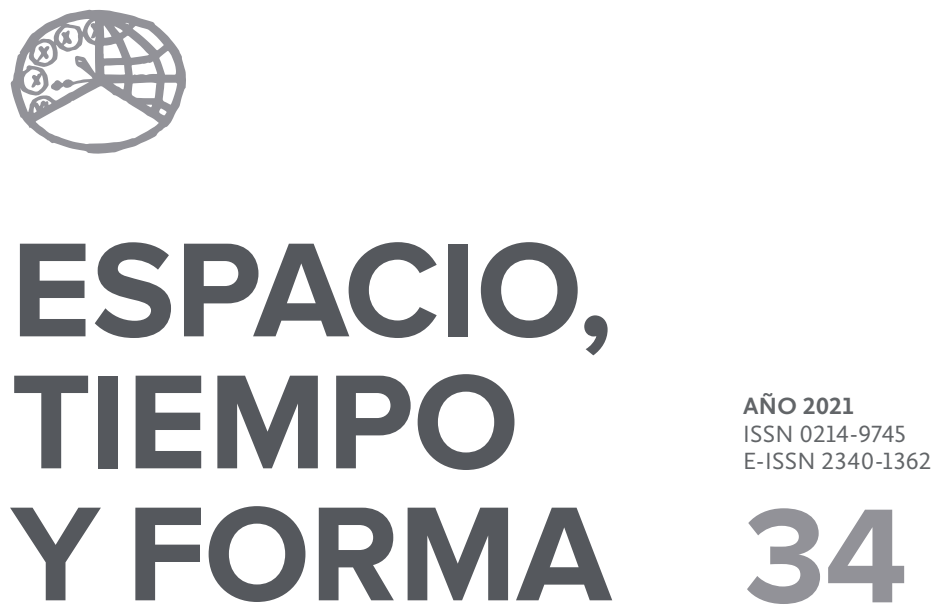

SERIE III HISTORIA MEDIEVAL

REVISTA DE LA FACULTAD DE GEOGRAFÍA E HISTORIA

VOLUMEN I

http://dx.doi.org/10.5944/etfiii.34.2021

\section{UกED}

UNIVERSIDAD NACIONAL DE EDUCACIÓN A DISTANCIA 
La revista Espacio, Tiempo y Forma (siglas recomendadas: ETF),

de la Facultad de Geografía e Historia de la UNED, que inició su publicación el año 1988, está organizada de la siguiente forma:

$$
\begin{aligned}
& \text { SERIE I - Prehistoria y Arqueología } \\
& \text { SERIE II - Historia Antigua } \\
& \text { SERIE III - Historia Medieval } \\
& \text { SERIE IV - Historia Moderna } \\
& \text { SERIE V - Historia Contemporánea } \\
& \text { SERIE VI - Geografía } \\
& \text { SERIE VII - Historia del Arte }
\end{aligned}
$$

Excepcionalmente, algunos volúmenes del año 1988 atienden a la siguiente numeración:
N. ${ }^{\circ} 1 \quad-$ Historia Contemporánea
N. ${ }^{\circ} 2-$ Historia del Arte
N. ${ }^{\circ} 3-$ Geografía
N. ${ }^{\circ} 4 \quad-$ Historia Moderna

ETF no se solidariza necesariamente con las opiniones expresadas por los autores.

UNIVERSIDAD NACIONAL DE EDUCACIÓN A DISTANCIA

Madrid, 2021

SERIE III - HISTORIA MEDIEVAL N. ${ }^{\circ} 34,2021$

ISSN 0214-9745 · E-ISSN 2340-1362

DEPÓSITO LEGAL M-21037-1988

URL: ETF III · HISTORIA MEDIEVAL · http://revistas.uned.es/index.php/ETFIII

DISEÑO Y COMPOSICIÓN

Carmen Chincoa Gallardo · http://www.laurisilva.net/cch

Impreso en España $\cdot$ Printed in Spain 
Espacio, Tiempo y Forma. Serie III. Historia Medieval es la revista científica fundada en I988 que publica el Departamento de Historia Medieval y Ciencias y Técnicas Historiográficas de la Facultad de Geografía e Historia de la UNED. Está dedicada al estudio de la Historia Medieval y acoge trabajos inéditos de investigación, en especial artículos que constituyan una aportación novedosa, que enriquezcan el campo de estudio que abordan y que ofrezcan una perspectiva de análisis crítico. Va dirigida preferentemente a la comunidad científica y universitaria, tanto nacional como internacional, así como a todos los profesionales de la Historia Medieval en general. Su periodicidad es anual y se somete al sistema de revisión por pares ciegos. La revista facilita el acceso sin restricciones a todo su contenido desde el momento de su publicación en edición electrónica. Espacio, Tiempo y Forma. Serie III. Historia Medieval se publica en formato electrónico y en papel.
Espacio, Tiempo y Forma. Serie III. Historia Medieval (Space, Time and Form. Series III. Medieval History) is a peerreviewed academic journal founded in I988 and published by the Department of Medieval History and Historiographical Sciences and Techniques at the Faculty of Geography and History, UNED. It is devoted to the study of Medieval History and is addressed to the Spanish and international scholarly community, as well as to professionals in the field of Medieval History. The journal welcomes previously unpublished articles, particularly works that provide an innovative approach, contribute to its field of research and offer a critical analysis. It is published annually. The journal provides complete open access to its content available online upon publication. Espacio, Tiempo y Forma. Serie III. Historia Medieval is published online and in print and is indexed in the databases and directories enumerated below.

Espacio, Tiempo y Forma. Serie III. Historia Medieval está registrada e indexada en Repertorios Bibliográficos y Bases de Datos nacionales e internacionales, como recomiendan los criterios de la Comisión Nacional Evaluadora de la Actividad Investigadora: LATINDEX, DICE, ISOC (CINDOC), RESH, INRECH, Dialnet, e-spacio UNED, CIRC 2.o (20I6), MIAR, FRANCIS, PIO, Ulrich's, SUDOC, ZDB, ERIH (ESF), REDIB, Repertorio de Medievalismo Hispánico, Directory of Open Access Journals (DOAJ), Emerging Sources Citation Index (ESCI), SCOPUS. La revista ha obtenido el Sello de Calidad de la FECYT (2018).

\section{EQUIPO EDITORIAL}

Edita: Departamento de Historia Medieval y Ciencias y Técnicas Historiográficas, Universidad Nacional de Educación a Distancia

Director del Consejo de Redacción: Enrique Cantera Montenegro (UNED)

Editores: Enrique Cantera Montenegro (UNED), Carlos Barquero Goñi (UNED) 
CONSEJO DE REDACCIÓN

Cristina Álvarez Millán

Departamento de Historia Medieval y Ciencias y Técnicas Historiográficas, UNED

Ana Arranz Guzmán

Universidad Complutense de Madrid

Carlos de Ayala Martínez

Universidad Autónoma de Madrid

Carlos Barquero Goñi

Departamento de Historia Medieval y Ciencias y Técnicas Historiográficas, UNED

Enrique Cantera Montenegro

Departamento de Historia Medieval y Ciencias y Técnicas Historiográficas, UNED

Ana Echevarría Arsuaga

Departamento de Historia Medieval y Ciencias y Técnicas Historiográficas, UNED

José María de Francisco Olmos

Universidad Complutense de Madrid

María Jesús Fuente Pérez

Universidad Carlos III de Madrid

Manuel Fernando Ladero Quesada

Departamento de Historia Medieval y Ciencias y Técnicas Historiográficas, UNED

Paulina López Pita

Departamento de Historia Medieval y Ciencias y Técnicas Historiográficas, UNED

José Miguel López Villalba

Departamento de Historia Medieval y Ciencias y Técnicas Historiográficas, UNED

José María Monsalvo Antón

Universidad de Salamanca

Isabel Montes Romero-Camacho

Universidad de Sevilla

Gonzalo Viñuales Ferreiro

Universidad Rey Juan Carlos

COMITÉ CIENTÍFICO

Vicente Ángel Álvarez Palenzuela

Universidad Autónoma de Madrid

Daniel Baloup

Université de Toulouse-Le Mirail

Vicente García Lobo

Universidad de León

María Estela González de Fauve

Universidad de Buenos Aires · Fundación para la Historia de España

César González Mínguez

Universidad del País Vasco 
Nikolas Jaspert

Ruhr-Universität Bochum, Alemania

DIRECTORA DE ETF SERIES I-VII

Yayo Aznar Almazán

Decana Facultad de Geografía e Historia, UNED

SECRETARIO DE ETF SERIES I-VII

Julio Fernández Portela

Departamento de Geografía, UNED

GESTORA PLATAFORMA OJS

Carmen Chincoa Gallardo

COMITÉ EDITORIAL DE ETF SERIES I-VII

Carlos Barquero Goñi, Departamento de Historia Medieval y Ciencias y Técnicas Historiográficas, UNED; Enrique Cantera Montenegro, Departamento de Historia Medieval y Ciencias y Técnicas Historiográficas, Uned; Pilar Díez del Corral Corredoira, Departamento de Historia del Arte, UneD; Carmen Guiral Pelegrín, Departamento de Prehistoria y Arqueología (Arqueología), Uned; Patricia Hevia Gómez, Departamento de Prehistoria y Arqueología (Arqueología), unED; Luiza lordache Cârstea, Departamento de Historia Contemporánea, UNED; M. ${ }^{a}$ Luisa de Lázaro Torres, Departamento de Geografía, Uned; David Martín Marcos, Departamento de Historia Moderna, Uned; José Antonio Martínez Torres, Departamento de Historia Moderna, UnED; Íñigo García Martínez de Lagrán, Departamento de Prehistoria y Arqueología (Prehistoria), UnED; Álvaro Molina Martín, Departamento de Historia del Arte, Uned; Francisco Javier Muñoz Ibáñez, Departamento de Prehistoria y Arqueología (Prehistoria), UNED; Rocío Negrete Peña, Departamento de Historia Contemporánea, UnED; Miguel Ángel Novillo López, Departamento de Historia Antigua, UnED.

CORRESPONDENCIA

Revista Espacio, Tiempo y Forma

Facultad de Geografía e Historia, UNED

c/ Senda del Rey, 7

28040 Madrid

e-mail: revista-etf@geo.uned.es 



\section{SUMARIO · SUMMARY}

\section{VOLUMEN I}

13 Artículos $\cdot$ Articles

15 Patricia A. Argüelles Álvarez

Peligros, inseguridades y problemas del viajero visigodo

Danger, Lack of Safety and Problems for the Visigothic Traveller

37 Carmen Barceló, Ana labarta, Josep Benedito \& José M. Melchor Cuatro cerámicas con epigrafía árabe del Museu de Borriana

Four Ceramic Pieces with Arabic Inscriptions in the Archeological Museum of Borriana

65 Carlos Barquero Goñ

Organización de la Orden de San Juan en Castilla durante los siglos XII y XIII The Organization of the Order of Saint John in Castile during the Twelfth and Thirteenth Centuries

113 Francisco de Paula Cañas Gálvez

Una infanta de Navarra en la corte de Castilla: escenarios políticos en torno a la configuración y evolución del Hostal y la casa de Blanca de Trastámara, Princesa de Asturias (I424-†I464)

A Princess of Navarre in the Court of Castile: Political Scenarios in the Configuration and Evolution of the Hostal and Royal Household of Blanca of Trastámara, Princess of Asturias (I424-†I464)

165 David Caramazana Malia

Las promociones artísticas de Alonso de Ejea, arzobispo y administrador perpetuo de la Archidiócesis de Sevilla y patriarca de Constantinopla (I403-I4I7)

The Artistic Patronage of Alonso de Ejea, Archbishop and Perpetual Administrator of the Archdiocese of Seville and Patriarch of Constantinople (I403-I4I7) 
203 Pedro Castillo Maldonado

Privilegios episcopales: la inviolabilidad de los obispos visigóticos y el delito de lesa majestad

Episcopal Privileges: The Inviolability of Visigothic Bishops and the Crime of Lèse-Majesté

227 Máximo Diago HERnANDO

Alonso de Fonseca, Obispo de Ávila, Cuenca y Osma, y el ascenso de un linaje de exiliados portugueses en la Castilla de los siglos XV y XVI Alonso de Fonseca, Bishop of Ávila, Cuenca and Osma, and the Promotion in Castile of an Exiled Noble Family from Portugal during the Fifteenth and Sixteenth Centuries

263 Antonio PIO DI Cosmo

Santa Brigida ed il Monte Gargano: un paesaggio dell'anima. La descrizione dell'ambiente come stratagemma d'ammaestramento morale Saint Brigid and Mount Gargano: A Landscape of the Soul. The Description of the Environment as a Device for Moral Instruction

Santa Brígida y el Monte Gargano: un paisaje del alma. La descripción del medio ambiente como estrategia de entrenamiento moral

293 FERRAN ESQUiLACHE

La 'fila' de agua valenciana y otras medidas de aforo. La verdadera naturaleza de un sistema de medición de caudales de origen andalusí

The Valencian Water 'Fila' and other Systems of Gauging Liquid Capacity. The Actual Nature of a Measurement System of Water Flow of Andalusí Origin

323 Alejandro Esteban Álvarez

Habices del Reino de Granada averiguados en I528 y I53I: la țā‘a nazarí de Órgiva (Alpujarra)

Habices of the Kingdom of Granada Ascertained in 1528 and I53I: The Nasrid tạa'a of Órgiva (Alpujarra)

359 Javier Gómez Gómez e Iñakı Martín Viso

Rationes y decimas: evidencias sobre la gestión de las sernas en el siglo Xl en el noroeste de la Península Ibérica

Rationes and Decimas: Some Evidences on the Management of Eleventh Century Sernas in Northwestern Iberia 
383 Santiago González Sánchez

Aportaciones de Paredes de Nava a las campañas militares del Infante Don Fernando, señor de la villa y regente de Castilla, contra el Reino Nazarí de Granada en I407 y en I4IO

The Contribution of Paredes de Nava to the Military Campaigns of the Infante Fernando, Lord of the Town and Regent of Castile, against the Nasrid Kingdom of Granada in 1407 and I4IO

429 ANTONI LLIBRER ESCRIG

Una máquina para la industria medieval. Los batanes del sur valenciano: integración y negocio. Nuevas aportaciones (I49O-I502)

A Machine for Medieval Industry. The Fulling Mills of the Valencian South: Integration and Business. New contributions (I49O-I502)

455 José Miguel López Villalba

Comunicación escrita y oral de la ordenanza municipal (siglos XV-XVI) Written and Oral Communication of Municipal Regulations (FifteenthSixteenth Centuries)

501 Emilio Martín Gutiérrez

El aprovechamiento de los recursos naturales: la grana en Andalucía occidental durante el siglo XV

The Use of Natural Resources: Grana Pigmentin Western Andalusia during the Fifteenth Century

\section{VOLUMEN II}

537 Vera-Cruz Miranda Menacho

Las finanzas de un heredero: Carlos de Aragón y Navarra (I42I-I46I)

A Crown Prince's Finances: Charles of Aragon and Navarre (I42I-I46I)

569 Raúl Morales Muñoz

Hacia una revalorización del conciliarismo hispano bajomedieval: el Defensorium Trium Conclusionum de Alfonso de Madrigal

Towards a Reappraisal of Late-Medieval Hispanic Conciliarism: Alfonso de Madrigal's Defensorium Trium Conclusionum 
605 David Nogales Rincón

Enrique III de Castilla (I390-I406) y la indagación de rentas: un proyecto regio para la búsqueda de mineros y tesoros a inicios del cuatrocientos Enrique III of Castile (I390-I406) and the Inquiry into Sources of Revenue: A Royal Project for the Quest of Mines And Treasures at the Turn of the Fifteenth Century

647 Gonzalo Oliva Manso

Seisenes y novenes. Tiempos de calma para la moneda castellano-leonesa (I282-I3I2)

The Seisén and the Novén. Times of Stability for the Castile-Leonese Currency (I282-I3I2)

685 Alberto Peña Fernández y Manuel García Alonso Una inscripción medieval inédita en la iglesia de San Miguel de Aguayo (Cantabria)

A Newly Found Medieval Inscription in the Church of San Miguel de Aguayo (Cantabria)

713 Rodrigo Pousa Diéguez

Configuración institucional de una villa costera: Muros en el tránsito de la Edad Media a la Edad Moderna

The Institutional Development of a Coastal Village: Muros between the Middle Ages and the Early Modern Times

745 Juan A. Prieto Sayagués

Las profesiones femeninas de la nobleza y de las oligarquías urbanas en la Castilla bajomedieval. Causas, dinámicas, privilegios y donaciones

Female Professions among the Nobility and the Urban Oligarchy in Late Medieval Castile. Causes, Dynamics, Privileges and Donations

815 María del Pilar Rábade Obradó

El miedo a la Inquisición en la Castilla de los Reyes Católicos

Fear of the Inquisition in Castile under the Catholic Monarchs

845 Carlos Manuel Reglero de la Fuente

EL abad contra el rey (y los regidores): conflicto de jurisdicciones y ejercicio del poder en Sahagún (I398-I4I7)

The Abbot versus The King (and the Town Councillors): Conflict between Jurisdictions and the Use of Power in Sahagún (I398-I4I7) 
881 Manuel Alejandro Rodríguez de la Peña

Eusebius and Alcuin on Constantine and Charlemagne as Wise Rulers:

Sapiential Rulership in Late Antiquity and the Early Middle Ages

Constantino y Carlomagno como gobernantes sabios en la obra de Eusebio de Cesarea y Alcuino de York: la realeza sapiencial en la Antigüedad Tardía y la Alta Edad Media

915 Antonio SÁnchez González

El Archivo de los Mariscales de Castilla y Marqueses de Malagón

The Archives of the Marshals of Castile and the Marquises of Malagón

\section{Estudios y comentarios}

951 Serafín Olcoz Yanguas

Apostilla al estudio Influencia de las redes nobiliarias en la expansión cristiana del siglo XII: el caso de Soria (ETF, 33, 2020)

Notes on the Article The Influence of Aristocratic Networks on the Christian Expansion of the Twelfth Century. The Case of Soria $(E T F, 33,2020)$

\section{Libros $\cdot$ Books}

969 CASTRIllo CASAdo, Janire, Las mujeres vascas durante la Baja Edad Media (María Jesús Fuente)

973 Crónica del rey Juan II de Castilla. Minoría y primeros años de reinado (I406I420). Garcia, Michel (edición y estudio) (Víctor MuÑoz Gómez)

981 Da Silva, Marcelo Cândido, História Medieval (Diego Carlo Améndolla SPÍNOLA)

987 Galende Díaz, Juan Carlos y Ávila SeoAne, Nicolás, El rodado regio hispánico. Fernando III de León y Castilla (I23O-I252) (MAURicio Herrero JIMÉNEZ)

989 GARcía IzQuiERdo, Iván, Frontera, fuero y concejos. El valle del Riaza en la Edad Media (siglos VIII-XII) (CARLOS BARQUERO GOÑI)

993 García IzQuierdo, Iván y Peterson, David (coords.), Camino y Señorío. Obra selecta de Luis Martínez García (Enrique Cantera Montenegro) 
995 González Paz, Carlos Andrés, O Bispado de Mondoñedo na Idade Media. Territorio, comunidade e poder (ENRIQue CANTERA Montenegro)

997 López Martínez, Amalia, Minutarios notariales de Estevo Pérez (Ourense, siglo XIV) (José Miguel López Villalba)

999 Miranda García, Fermín y López de Guereño Sanz, María Teresa (eds.), La muerte de los príncipes en la Edad Media. Balance y perspectivas historiográficas (ANA Echevarría Arsuaga)

1003 Motis Dolader, Miguel Ángel, Vivencias, emociones y perfiles femeninos. Judeoconversas e Inquisición en Aragón en el siglo XV (ANA EcheVARRía ArSUAGA)

1007 Solórzano Telechea, Jesús Ángel y Martín Pérez, Fernando (coords.), Rutas de comunicación marítima y terrestre en los reinos hispánicos durante la Baja Edad Media. Movilidad, conectividad y gobernanza (ENRIQUe José Ruiz Pilares)

1013 Torre, Sandra de la - Etxeberria, Ekaitz - Díaz de Durana, José Ramón (coords.), Valer más en la tierra. Poder, violencia y linaje en el País Vasco bajomedieval (EnRIQue CANTERA Montenegro)

1015 TRIllo SAN José, Carmen, La Vega de Granada a partir de documentación árabe romanceada inédita (I457-I494). Estudio, edición e índices (INMACULADA GONZÁlez SopeÑA)

1019 Val Valdivieso, M. ${ }^{a}$ Isabel - Villanueva Zubizarreta, Olatz (Coords.), Pero Ansúrez. El conde, su época y su memoria (Enrique CANTERA Montenegro)

1021 Villanueva Morte, Concepción y Fernández de Córdova Miralles, Álvaro, El embajador Claver. Diplomacia y conflicto en las «Guerras de Italia» (I495-I504) (ENRIQUe CANTERA MONTENEGRO)

1023 Normas de publicación · Authors Guidelines 


\section{ARTÍCULOS · ARTICLES}

\section{VOLUMEN I}





\title{
ALONSO DE FONSECA, OBISPO \\ DE ÁVILA, CUENCA Y OSMA, Y \\ EL ASCENSO DE UN LINAJE DE \\ EXILIADOS PORTUGUESES EN LA \\ CASTILLA DE LOS SIGLOS XV Y XVI
}

\section{ALONSO DE FONSECA, BISHOP OF ÁVILA, CUENCA AND OSMA, AND THE PROMOTION IN CASTILE OF AN EXILED NOBLE FAMILY FROM PORTUGAL DURING THE FIFTEENTH AND SIXTEENTH CENTURIES}

\author{
Máximo Diago Hernando
}

Recepción: 2020/06/18 . Comunicación de observaciones de evaluadores: 2020/11/02 . Aceptación: 2020/11/24

DOI: https://dx.doi.org/10.5944/etfiii.34.2021.30045

\section{Resumen ${ }^{2}$}

Contribución al estudio de la circulación de las élites nobles en los reinos hispanos en el período bajomedieval. Desde fines del siglo XIV numerosos nobles portugueses se exiliaron en el reino de Castilla, donde protagonizaron exitosas carreras de ascenso social y político. En este artículo se trata de realizar una aportación al conocimiento de este proceso, prestando atención a un linaje de rango medio, el de los Fonseca, que se estableció en la ciudad de Toro a raíz del exilio en Castilla de la reina Beatriz. Presenta la peculiaridad de que muchos de sus miembros tuvieron exitosas carreras eclesiásticas y ocuparon numerosas sedes episcopales en Castilla, e incluso disfrutaron de influencia en la Curia. En esta ocasión se centrará el análisis en uno de los menos conocidos de dichos eclesiásticos, Alonso de Fonseca, que fue obispo de Ávila, Cuenca y Osma. Se presta especial atención a la faceta política de su trayectoria, en la ciudad de Toro, y a su proyecto de

1. Instituto de Historia. CSIC (Madrid). C.e.: máximo.diago@cchs.csic.es. ORCID: 0000-0003-2118-5086.

2. Este trabajo ha sido realizado en el marco del proyecto de investigación «Transferencias humanas, culturales e ideológicas entre los reinos ibéricos. Siglos XIII-XV». Investigadores principales, Isabel Beceiro Pita y César Olivera Serrano. Financiado por la DGCYT (Gobierno de España). Referencia. HAR 2019-89398-P. 
encumbramiento social y político de su hijo bastardo, Gutierre de Fonseca, que llegó a ser uno de los miembros más influyentes del grupo oligárquico de Toro, sobre todo tras la derrota de los comuneros, contra los que militó.

\section{Palabras clave}

Siglo XV; siglo XVI; nobles portugueses; obispos; Castilla.

\section{Abstract}

This is a case study of the movement of noble élites in the Iberian kingdoms during the late Middle Ages. By the end of the fourteenth century, many Portuguese nobles sought exile in the kingdom of Castile where they achieved successful careers and advanced socially and politically. The aim of this article is to examine a case study of this process, focussing on a middle rank noble family, that of the Fonsecas, that took residence in the city of Toro, after the exile in Castile of Queen Beatriz. One curious aspect of this family is that many of its members were successful ecclesiastics, that occupied numerous episcopal sees in the kingdom of Castile, and were also influential in the papal court. This case study will centre on one of the lesser famous of these ecclesiastics, Alonso de Fonseca, who was bishop of Ávila, Cuenca and Osma. Special attention is given to the political aspects of his career in the city of Toro, and to his project of social and political promotion of his bastard son, Gutierre de Fonseca who became one of the most influential members of the noble oligarchy of Toro, especially after the defeat of the Comuneros, against which he fought.

\section{Keywords}

Fifteenth Century; Sixteenth Century; Portuguese Nobles; Bishops; Castile. 


\section{INTRODUCCIÓN}

La circulación de los miembros de las élites nobles en los reinos hispanos de la Baja Edad Media es un fenómeno de importancia crucial al que se ha de prestar atención para profundizar en la caracterización del perfil sociopolítico de estos reinos, del que algunas escuelas historiográficas, influidas por presupuestos «nacionalistas», han tendido a ofrecer una imagen deformada, al servicio de su propio proyecto ideológico o político.

Se ha llamado la atención sobre la incorporación a la sociedad política castellana de los siglos XIV y XV de nobles de origen portugués, que protagonizaron procesos de ascenso social que les encaramaron a los más elevados escalones de la jerarquía nobiliaria castellana ${ }^{3}$. Se ha llegado a hablar incluso de la formación de un «partido portugués», con notoria influencia en la vida política de la Castilla del siglo XV. cuyo programa habría consistido en el debilitamiento de la Monarquía. Así lo ha sostenido Romero Portilla ${ }^{4}$, aunque la validez con carácter general de esta tesis ha sido cuestionada después por otros autores, como Olivera Serrano5.

Entre estos linajes de origen portugués está el de los Fonseca. No puede decirse que resulte desconocido para la historiografia, aunque, por ejemplo, llama la atención que Romero Portilla apenas le preste atención, pese al gran número de linajes que toma en consideración. Sus primeros pasos en Castilla, a donde el linaje se trasladó como consecuencia de haberse mantenido fiel a la reina Beatriz, segunda esposa de Juan I, hija única y heredera legítima del monarca portugués Fernando I y de su esposa Leonor Téllez, han sido estudiados por César Olivera en sus trabajos sobre la trayectoria en el exilio de esta reina, tras la batalla de Aljubarrota y la consolidación en el trono portugués del maestre de Avis, secularizado ${ }^{6}$. Este autor ha dedicado especial atención a la figura de Pedro Rodríguez de Fonseca, muerto en I4I9, quien, habiendo servido como embajador al rey Pedro I de Portugal, tras exiliarse en Castilla en seguimiento de la reina Beatriz, terminó siendo consejero de Juan I y guarda mayor de Juan Il, y acabó sus días en la ciudad de Toro, donde otorgó testamento en I4I97. Por otro lado ha puesto de relieve la relevancia de la figura de su hijo, Pedro de Fonseca, cardenal diácono de Sant 'Angelo, quien protagonizó una exitosa carrera en el seno de la Iglesia. Lo consiguió, primero, gracias a los vínculos que estableció con el Papa Benedicto XIII, en la línea de otros muchos eclesiásticos portugueses opuestos al

3. Sin ánimo de ser exhaustivo cabe citar entre otras obras que han abordado esta cuestión MITRE, 1966, ROMERO, 2011 y OLIVERA, 2005.

4. ROMERO, 2011.

5. Olivera, 2008.

6. Olivera, 2005, pp. 266-275.

7. Olivera, 2002. 
urbanista Juan I, rey de Portugal. Y después, como consecuencia del buen acomodo que logró encontrar con el nuevo Papa, Martín V, tras el Concilio de Constanza ${ }^{8}$.

Estos estudios han demostrado la inicial conexión de los Fonseca portugueses con la ciudad de Toro, y puesto de relieve las oportunidades que para su promoción les ofreció la Iglesia. Dar continuidad a estas investigaciones ofrece un indiscutible interés, si se dirige la atención a otros miembros del linaje Fonseca procedentes del mismo tronco arraigado en Toro, que protagonizaron procesos de ascenso social y político gracias a sus exitosas carreras eclesiásticas, complementadas con posiciones de influencia en el ámbito cortesano.

\section{LOS FONSECA DE TORO EN LA IGLESIA CASTELLANA}

Siguiendo la estela del cardenal Pedro Rodríguez de Fonseca, fueron muchos los miembros de su linaje arraigados en Castilla que progresaron en la Iglesia, pero que, a diferencia de aquél, no dieron el salto a la Curia romana, sino que desarrollaron sus carreras íntegramente en Castilla. Hasta cuatro prelados que llevaron el nombre de Alonso de Fonseca, estrechamente emparentados entre sí, despuntaron por sus exitosas trayectorias en el seno de la Iglesia castellana durante los siglos XV y XVI. A ellos se ha de añadir un quinto personaje vinculado con ellos por lazos de parentesco, Juan Rodríguez de Fonseca, quien culminó su carrera ocupando la sede de Burgos durante el reinado de Carlos I, tras haber pasado previamente por las de Badajoz, Córdoba y Palencia. No vamos a ofrecer aquí información detallada de todos estos prelados y los vínculos de parentesco que les unen ${ }^{9}$. Nos limitaremos a precisar que nos estamos refiriendo a Alonso de Fonseca y Ulloa, obispo de Ávila entre I445 y I454, y ascendido después a arzobispo de Sevilla ${ }^{\mathrm{Io}}$, su sobrino Alonso de Fonseca y Acevedo, arzobispo de Sevilla y Santiago, que ostentó el título honorífico de Patriarca de Alejandría ${ }^{\text {II }}$ y el hijo bastardo de éste, Alonso de Fonseca y Ulloa, el cual fue primero arzobispo de Santiago y más adelante, en I523, pasó a ocupar la vacante del arzobispado de Toledo tras la muerte del flamenco Guillermo de Croy en I52I. Estos tres célebres eclesiásticos proporcionan ilustraciones paradigmáticas de los niveles a los que en aquellos tiempos llegó el nepotismo y la utilización de la Iglesia como instrumento de engrandecimiento personal por determinadas familias que contaban con las necesarias conexiones.

8. Olivera, 2014 .

9. AlCOCER, 1926, pp. 9 y ss. Jorge Díaz Ibáñez sostiene que los Fonseca fueron el linaje que en Castilla proveyó el mayor número de sedes, once, pero no precisa cuáles. También destaca que fue el linaje que proporcionó mayor número de obispos en el siglo XV y principios del XVI, con siete, pero tampoco precisa quiénes fueron. DíAZ, 2019, p. 17.

10. Sobre este personaje, con intensa participación en la vida política castellana puede verse FrANCO, 2006 y GONZÁLEZ, 2019 .

11. Sobre él, en su faceta como arzobispo de Santiago, puede consultarse el artículo monográfico que le dedicó VÁZQUEZ, 2000. 
Conviene recordar que Alonso de Fonseca y su sobrino homónimo decidieron en I46o permutarse las sedes de Santiago y Sevilla, dos de las más prestigiosas del reino, de modo que el que era arzobispo de Santiago pasó a serlo de Sevilla, y viceversa, aunque poco tiempo después el tío quiso revertir el canje, provocando un enfrentamiento con el sobrino,que desestabilizó gravemente la vida política de Sevilla por un tiempo ${ }^{12}$. Pero, por si esto fuera poco, el sobrino tiempo después dio un paso aún más osado y que se podría considerar escandaloso. En efecto, Alonso de Fonseca y Avecedo consiguió traspasar años después la sede arzobispal de Santiago a su propio hijo bastardo, llamado Alonso de Fonseca y Ulloa, quien, como acabamos de indicar, acabó su carrera en la sede primada de Toledo.No ha faltado quien ha comentado el parecido de estas operaciones con las que en la Curia romana sacó adelante el cardenal Borgia, que terminó su agitada trayectoria ocupando el solio pontificio con el nombre de Alejandro $\mathrm{VI}^{13}$.

Estos tres eclesiásticos que comparten el nombre de Alonso de Fonseca forman un bloque compacto dentro de este peculiar linaje de origen portugués arraigado en Toro. En la bibliografía especializada abundan las referencias a ellos, y muy especialmente a la huella que dejaron en ciudades emblemáticas como Santiago o Salamanca. No va a ser, por tanto, el propósito del presente trabajo profundizar en el análisis de estos tres singulares personajes, que proporcionan materia más que suficiente para otros estudios monográficos. En contrapartida, centraremos nuestra atención de forma preferente en el cuarto Alonso de Fonseca, el que sucesivamente ocupó las sedes de Ávila, Cuenca y Osma. Este prelado, a diferencia de sus parientes homónimos, no ha merecido tanta atención por parte de los investigadores. Salvando las noticias que sobre él proporciona el clásico estudio de Loperráez Corvalán sobre los obispos de Osma, que en algunos casos hay que tomar con precaución ${ }^{\mathrm{I}}$, sólo cabe destacar un pequeño trabajo monográfico relativo a él, centrado en el estudio del proceso de acumulación por su parte de un gran patrimonio mediante compras, con el objetivo de posibilitar la promoción social y política de uno de sus hijos bastardos, llamado Gutierre, quien llegó a ser regidor de Toro $^{15}$. Su figura queda oscurecida por la de sus homónimos que ocuparon sedes mucho más prestigiosas como las de Santiago, Sevilla y Toledo, y por supuesto también por la de su primo, Juan Rodríguez de Fonseca, quien desempeñó un destacado papel político en el ámbito cortesano durante la regencia de Fernando el Católico y a comienzos del reinado de Carlos I. Pese a que no alcanzó el relieve de éstos, la figura histórica de Alonso de Fonseca, obispo de Ávila, Cuenca y Osma, ofrece, sin embargo, un indiscutible interés para el investigador de la Castilla bajomedieval desde muy diversos puntos de vista, pues permite

\footnotetext{
12. Ollero, 2010, Franco, 2006, y Ladero, 2015, pp. 145-146.

13. Franco, 2010, p. 570.

14. LOPERRÁEZ, 1978, pp. 388-9.

15. Franco, 2010.
} 
ilustrar aspectos fundamentales de la realidad política y social de dicho reino en época de los Reyes Católicos.

El estudio de su trayectoria nos proporciona una prueba adicional de la importancia que la Iglesia tuvo para el ascenso de los miembros del linaje Fonseca, proporcionándoles una útil plataforma para su promoción también en la esfera secular. Se trata de una circunstancia sobre la que ya llamó la atención hace siglos Gonzalo Fernández de Oviedo, cuando en su célebre obra Batallas e Quinquagenas sostuvo que los diversos prelados del linaje Fonseca «le han dado la mayor parte e mejor renta que esta casa tiene» ${ }^{16}$.

En cualquier caso, el de los Fonseca no fue el único linaje de la ciudad de Toro que despuntó en la Castilla de los siglos XV y XVI por las exitosas carreras eclesiásticas de sus miembros. Otros linajes toresanos, muy estrechamente vinculados con ellos por lazos de parentesco, proporcionaron a la Iglesia personajes ilustres en este mismo período. Baste recordar los casos del dominico fray Diego de Deza (I443-I523), que fue sucesivamente obispo de Zamora, Salamanca, Jaén y Palencia, y culminó su carrera como arzobispo de Sevilla, y de su sobrino, el cardenal Juan Pardo de Tavera, que fue arzobispo de Toledo, al final de una exitosa carrera eclesiástica iniciada como obispo de Ciudad Rodrigo en $1514^{17}$.

Esta proliferación de eclesiásticos influyentes entre las familias de la oligarquía noble de Toro resulta aún más sorprendente si se tiene en cuenta que esta ciudad no formaba parte del selecto grupo de las que eran capitales de diócesis, y sede por consiguiente de un cabildo catedralicio. Ciertamente no se trataba de un fenómeno excepcional, pues entre las dieciocho privilegiadas ciudades que a finales del reinado de los Reyes Católicos conservaban el derecho a estar representadas en Cortes, tras la conquista de Granada en I492, además de Toro había otras que compartían esta característica. Entre ellas estaba incluso Valladolid, que desde otros puntos de vista formaba parte del grupo de ciudades de máximo rango de la Corona de Castilla, muy frecuentada por la Corte y sede de importantes instituciones de la Monarquía y de una de las principales universidades de la Península Ibérica. También era el caso de Soria, en la submeseta norte, y de Guadalajara y Madrid en la submeseta sur, además de Murcia, que no ostentaba la capitalidad del obispado de Cartagena, aunque sí era la sede de su catedral.

\footnotetext{
16. Tomamos la cita de Franco, 2010, p. 569.

17. Sobre la ascendencia portuguesa de estos dos influyentes eclesiásticos nacidos en la ciudad de Toro, OLIVERA, 2005 , p. 265.
} 


\section{ALONSO DE FONSECA Y JUAN RODRÍGUEZ DE FONSECA: BREVES REFERENCIAS BIOGRÁFICAS}

Alonso de Fonseca nació en Toro, como hijo primogénito de Pedro de Ulloa y Fonseca y Doña Isabel de Quijada ${ }^{18}$. Según Loperráez Corvalán sirvió a los Reyes Católicos en las guerras de Portugal, peleando en la batalla de Toro, y en premio a estos servicios dichos monarcas le proporcionaron en I48o el obispado de Ávila, vacante por muerte de muerte de Martín Fernández de Vilches, quien habría fallecido el I3-XI-I479 ${ }^{\text {I9 }}$. Pero esta fecha del fallecimiento de Martín Fernández de Vilches parece estar equivocada, pues según otros autores como Cañas Gálvez ocurrió el I3 de noviembre, pero de I469 ${ }^{20}$. Por otra parte el propio Franco Silva da a conocer un documento del año I477 en que Alonso de Fonseca ya aparece identificado como obispo de Ávila, relativo a la compra del señorío de Villanueva de Cañedo al regidor de Toro, Alonso de Valencia ${ }^{21}$. Loperráez proporciona algunos otros datos que prueban que disfrutó de cierto favor en la Corte de los Reyes Católicos, quienes, según este autor, le encomendaron el desempeño de algunas misiones diplomáticas relevantes, que ofrecen evidentes paralelismos con las que para los mismos monarcas desempeñó su primo, también prelado, Juan Rodríguez de Fonseca. En concreto sostiene Loperráez que acompañó a la infanta María cuando partió a contraer matrimonio con el rey de Portugal, Manuel, viudo de la princesa Isabel. Y también le nombraron los reyes para que acompañase a la infanta Catalina a Inglaterra cuando partió para casarse con el príncipe Arturo, aunque el que consta que efectivamente la acompañó fue su primo, el ya mencionado Juan Rodríguez de Fonseca, que fue un reconocido especialista en la organización de armadas y viajes por $\operatorname{mar}^{22}$. En la misma línea Loperraéz proporciona otras noticias que abundan en demostrar la fuerte relación de confianza que los Reyes Católicos mostraron hacia este prelado, entre las que destaca la relativa a la elección de sus casas principales en la ciudad de Toro para que en ellas se iniciase el II de enero de 1505 la celebración de las Cortes, las primeras que se reunieron después de la muerte de Isabel la Católica ${ }^{23}$. De estas casas se dice en la documentación que eran las más «principales» existentes en la ciudad de Toro. Se localizaban en un lugar muy céntrico, junto a la colegiata, según se hace constar en el documento de fundación de mayorazgo a favor de su hijo Gutierre del año 1505, al que fueron incorporadas. En la misma línea también apunta el hecho de que, cuando en I5I9 Carlos I contempló la posibilidad de trasladar a su

18. Franco, 2010, publica el testamento otorgado por su madre, Isabel de Quijada, viuda de Pedro de Ulloa, en Toro, 2-XII-1488, en pp. 594-8.

19. LOPERRÁEZ, 1978, t. I, p. 388.

20. CAÑAS, 2012, pp. 332-3.

21. FRANCO, 2010, p. 571.

22. LOPERRÁEZ, 1978, t. I, p. 389

23. LOPERRÁEZ, 1978, t. I, pp. 390-1. 
madre la reina fuera de Tordesillas, por la amenaza de problemas sanitarios en dicha villa, y pensó en que residiese en la ciudad de Toro, trasladó a Gutierre de Fonseca, el hijo del obispo que había heredado su mayorazgo, el ruego de que dejase libres dichas casas para que pudiese instalarse en ellas la reina. Justificó su decisión con el argumento de que «he sido informado que en la dicha ciudad no hay otras casas más principales ni donde la reina pueda posar mejor que en las vuestras ${ }^{24}$. Pero, en honor a la verdad, una cédula con idéntico contenido fue dirigida al regidor de Toro Juan Rodríguez de Fonseca. En cualquier caso ni uno ni otro tuvieron finalmente que poner sus casas principales a disposición de la reina, porque ésta no llegó a ser trasladada a Toro, y seguía en Tordesillas cuando se desencadenó la revuelta comunera.

Pese a estas noticias aportadas por Loperráez, algunas de imposible comprobación, la relación de este prelado con los Reyes Católicos no estuvo exenta de graves tensiones, y se vio afectada por decisiones contradictorias. Así, en unas ocasiones Alonso de Fonseca recibió el pleno apoyo de los monarcas, que evidenciaba trato de favor, pero en otras éstos actuaron con dureza frente a él. Por contraste la influencia alcanzada en la Corte por su primo Juan Rodríguez de Fonseca, hijo de un hermano de su padre, fue mucho mayor y careció de tantas sombras. A pesar de ello, Alonso de Fonseca gustó de identificarse como «oidor de la Audiencia de la reina y de su Consejo», aunque no podemos afirmar si se trataba de meros títulos honorificos, mientras que en el caso de su primo el desempeño efectivo de funciones de gran responsabilidad en el aparato burocrático de la Monarquía está fuera de toda duda, pues ha dejado abundante huella en la documentación.

Al margen de por las conexiones cortesanas que le atribuye Loperráez, la trayectoria de Alonso de Fonseca ofrece interés por el hecho de que pasó por tres sedes episcopales diferentes, y su traslado de unas a otras se produjo en circunstancias un tanto irregulares. Desconocemos los motivos que le llevaron a abandonar la sede de Ávila, más próxima a su ciudad natal de Toro, donde siempre tuvo centrados sus intereses políticos, por la de Cuenca. Mejor informados estamos sobre el procedimiento que se siguió para su paso de la sede conquense a la oxomense, en virtud de un acuerdo de permuta con un poderoso eclesiástico de la Curia romana, sobrino del Papa Sixto IV, el cardenal de San Jorge, Rafael Sansoni Riario. Este eclesiástico absentista, que no llegó a poner sus pies en tierras castellanas, a pesar de que en ellas acumuló importantes beneficios eclesiásticos, ya había manifestado interés con anterioridad por la sede conquense, Fue en I479, cuando su tío el Papa le designó para ocuparla, tras la muerte del titular, el cardenal Antonio Jacobo de Veneris. Pero no lo logró porque los Reyes Católicos opusieron una tenaz resistencia a admitirle, y lograron que finalmente, tras varios años de

24. AGS =Archivo General de Simancas, Patronato Real, 69-57. Cédula de Barcelona 15-XII-1519, suscrita por el secretario Francisco de los Cobos. 
litigio, el Papa accediese a renunciar a su propósito inicial, consintiendo que en Cuenca quedase como obispo Alonso de Burgos, el candidato de los monarcas castellanos, a cambio de que a su sobrino se le concediese como compensación la sede de Salamanca. Más adelante el cardenal de San Jorge, por considerar la de Salamanca sede de poco prestigio, logró que se le trasladase a la de Osma, a raíz de la promoción de Pedro González de Mendoza, que ocupaba dicha sede, al arzobispado de Toledo ${ }^{25}$.

Permaneció el cardenal genovés poco tiempo en la sede oxomense porque en 1493 llegó a un acuerdo con Alonso de Fonseca para permutar sus sedes. Sin duda para el italiano la de Cuenca presentaba ciertas ventajas, porque se insertaba plenamente en el ámbito de actuación de los mercaderes y financieros genoveses que operaban en la Península Ibérica, por su cercanía a Valencia, una de las principales bases de operaciones de los hombres de negocios italianos en la Península Ibérica en el siglo XV. Por ello le había de resultar más fácil encontrar personas dispuestas a poner a su disposición en Roma las rentas que le correspondía percibir como obispo en Castilla, que no era una empresa exenta de dificultades en las circunstancias de la época ${ }^{26}$.

El paso de Alonso de Fonseca de Cuenca a Osma estuvo acompañado de algunas pequeñas tensiones, sobre las que no disponemos, sin embargo, de suficientes detalles. Nos consta que los reyes llegaron a ordenarle por una provisión fechada en julio de 1493 que hiciese entrega de las fortalezas de Huerta y Monteagudo, pertenecientes a la dignidad episcopal conquense, al maestresala Antonio de Fonseca, para que éste las tuviese en depósito en nombre de los reyes ${ }^{27}$. Dado que este último era un personaje muy próximo al nuevo obispo de Osma, pues se trataba de su primo, hermano además del obispo Juan Rodríguez de Fonseca, no parece que la orden de hacerle entrega de las fortalezas resultase demasiado gravosa. Pero resulta llamativo que meses después de haber dejado de ser obispo de Cuenca continuase manteniendo el control de algunas de las fortalezas pertenecientes a dicha dignidad.

Su última etapa, como obispo de Osma, no fue pródiga en acontecimientos de índole política. No faltaron tensiones y conflictos, de muy variada naturaleza, en bastantes casos relacionados con la percepción de las rentas pontificales ${ }^{28} \mathrm{O}$ el ejercicio de la jurisdicción en algunos lugares de señorío de la mitra, como Ucero. También tuvo que pleitear, en apoyo de algunos de sus vasallos, en los

25. AzCONA, 1960, pp. 129 y 132-4 y DIAGO, 1997, pp. 139-142.

26. Sobre la colaboración de hombres de negocios genoveses con el cardenal de San Jorge durante su etapa como obispo de Cuenca, DIAGO, 1997. Para la historia del obispado de Cuenca en el período bajomedieval interesa Díaz, 2003.

27. AGS, RGS (=Registro General del Sello), VII-1493, fol. 68. Provisión dirigida a Alonso de Fonseca, obispo de Osma.

28. Entre los pleitos que siguió por la recaudación de rentas cabe destacar el seguido contra Gonzalo de Terradillos, principal, y Juan de Lisas, Pedro de Laredo y Alonso de Burgos, quienes habían arrendado los pontificales de Aranda de Duero por 360.000 mrs. La ejecutoria de este pleito en AChV (=Archivo de la Real Chancillería de Valladolid), RE (=Registro de Ejecutorias), C. (=Caja) 197, III-1505. También por la cuantía del arrendamiento de los pontificales, en este caso de Soria, pleiteó con el bachiller Alonso Rodríguez, vecino de esta ciudad. AChV, RE, C. 202, X 1505. 
enfrentamientos que éstos mantuvieron con los vecinos de otros lugares de señorío limítrofes. Es el caso de las tensiones que poco después de su traslado a Osma se desataron entre sus vasallos, vecinos de la villa de El Burgo de Osma, sede del cabildo catedral, y los vecinos de la ciudad de Osma, capital nominal del obispado, que eran vasallos del marqués de Villena, Juan Pacheco, en torno a la regulación del derecho a cazar y pescar en el río Ucero, y de otros aprovechamientos de términos $^{29}$. La implicación de Alonso de Fonseca en este litigio fue, sin embargo, escasa, pues ya se venía arrastrando desde mucho antes de que él se convirtiese en obispo de Osma.

Caso parecido es el de los pleitos que siguió con la Mesta por el cobro de derechos de pontaje a los ganados trashumantes que se desplazaban a las comarcas de pastos de invernadero desde las sierras sorianas y cameranas. Por otra parte fue un prelado eminentemente absentista, que no prodigó sus estancias en los lugares del obispado. Pese a ello, al otorgar su testamento, tuvo un recuerdo para este obispado, mientras que nada dejó dispuesto respecto a los otros dos en que había desempeñado funciones pastorales, los de Ávila y Cuenca. En efecto, designó como heredera universal de todos sus bienes, con excepción de los que habían sido incorporados al mayorazgo fundado en favor de su hijo Gutierre, a la iglesia catedral de El Burgo de Osma, a cambio de que el prior y cabildo quedasen obligados a celebrar una memoria de misas por su alma ${ }^{30}$. Loperráez precisa que se trató de una memoria de misas que se habían de decir todos los sábados en honor de Nuestra Señora, solemnemente, con órgano, con dotación de 8000 mrs. Y añade que costeó las rejas de hierro de la capilla mayor y coro, que se trabajaron en la ciudad de Toledo ${ }^{3 \mathrm{I}}$. No obstante el cumplimiento de estas disposiciones testamentarias en favor de la catedral y cabildo de El Burgo de Osma no fue fácil. Para resolver los conflictos que pudiesen surgir Alonso de Fonseca ordenó que el prior y cabildo se concertasen con su contador y mayordomo, designando para que interviniese como «tercero» en caso de que no lograsen ponerse de acuerdo al prior del monasterio de San Jerónimo de Espeja. Pero las diferencias debieron ser irreconciliables, pues finalmente se inició pleito entre dicho cabildo y el hijo y principal heredero del difunto obispo, Gutierre de Fonseca, sobre el reparto de los bienes muebles que habían quedado a la muerte del prelado, que se seguía arrastrando en I5I3, pese a que había fallecido el ig de diciembre de $1505^{32}$.

En cualquier caso, pese a esta generosidad demostrada hacia la catedral de El Burgo de Osma, Alonso de Fonseca dispensó comprensiblemente mucha más atención a las instituciones eclesiásticas de su ciudad natal de Toro. Allí, siempre

29. AChV, Lapuerta, F.(=Fenecidos) C. 314-6. Se incorporan varias provisiones de los Reyes Católicos del año 1494

30. Publica el testamento Franco, 2010, pp. 620-631.

31. LOPERRÁEZ, 1978, t. I, p. 391.

32. AChV, RE, C. 288, IX-1513. Receptoría en el pleito entre el cabildo de El Burgo de Osma, de una parte, y Gutierre de Fonseca, de otra. 
según Loperráez, contribuyó a la financiación de obras para la conclusión del edificio de la colegiata, junto a la cual se ubicaban sus casas principales incorporadas al mayorazgo, y de gran parte de las que se realizaron en el convento de San Francisco ${ }^{33}$ . En consonancia con este interés demostrado a lo largo de toda su vida por la ciudad que le vio nacer, fue en ella también donde dispuso que se le enterrase. Allí otorgó su testamento, el 8 de noviembre de 1505 , en el que dispuso que su cuerpo fuese depositado en una capilla de la iglesia del convento dominico de San Ildefonso, junto a sus padres. También ordenó que a dicha capilla fuese trasladado el cuerpo de su tío Alonso de Fonseca, que había sido arzobispo de Sevilla ${ }^{34}$.

Dicho testamento nos informa también sobre la estrecha relación que existió entre el obispo de Osma y su primo Juan Rodríguez de Fonseca, obispo de Burgos. Le eligió, en efecto, para que fuese uno de sus testamentarios, asignándole además en un codicilo un legado de 300 ooo mrs. para compensarle por su trabajo de albacea. No profundizaremos aquí en reconstruir la biografía de este otro prelado del linaje Fonseca, sobradamente conocido para la historiografía especializada en los reinados de Reyes Católicos y Carlos I, que ha resaltado su participación en misiones diplomáticas, su eficacia en la organización de armadas y su creciente control de la gestión de los negocios de Indias, en compañía con Lope Conchillos ${ }^{35}$. Había nacido en Toro en I45I del matrimonio formado por un hermano de Don Alonso de Fonseca, arzobispo de Santiago, llamado Fernando, y de su segunda esposa Doña Teresa de Ayala. Abundan los hitos destacados en su carrera, tales como su participación en la misión diplomática en 1492 para concertar los matrimonios de Juan y Juana, hijos de los Reyes Católicos, con Margarita y Felipe de Habsburgo, hijos del emperador Maximiliano y de María de Borgoña. Poco después se le designó para organizar el segundo viaje de Colón a América, y a partir de entonces creció sin parar su influencia en la gestión de los negocios de Indias, mientras que paralelamente se iba menoscabando la del propio descubridor genovés, a quien terminó desplazando.

Entre las trayectorias de Alonso de Fonseca y su primo Juan Rodríguez de Fonseca,que fue sucesivamente obispo de Badajoz, Córdoba, Palencia y Burgos, pueden encontrarse numerosos paralelismos, aunque también ciertas diferencias y contrastes. Al margen de que en este último faltó el móvil de la acumulación de patrimonio para dejar bien dotado a un hijo bastardo, que fue fundamental para explicar la trayectoria de Alonso, también mostró menos interés por los asuntos políticos de su ciudad natal de Toro, respecto a la que guardó una cierta distancia.

Pero no se mantuvo completamente al margen de los acontecimientos que marcaron la vida política de esta ciudad realenga con voto en Cortes. Lo demuestran

33. LOPERRÁEZ, 1978, t. I, p. 391.

34. FRANCO, p. 582

35. Entre la abundante bibliografía sobre este personaje puede consultarse ALCOCER, 1926, TERESA, 1960 y SAGARRA, 1998. Sobre su papel en la gestión de los negocios de Indias GIMÉNEZ, 1953. 
los sucesos que tuvieron lugar en la etapa final de su vida, durante la guerra de las Comunidades. Vecinos de Toro formaban entonces parte de su clientela, y dieron buena prueba de su fidelidad a su persona militando en el bando realista, pese a que los rebeldes comuneros se hicieron con el control del gobierno de la ciudad. En efecto, varios criados suyos vecinos de Toro protestaron cuando en los meses que siguieron a la derrota comunera de Villalar se les quiso obligar por las autoridades urbanas a contribuir en los repartimientos que se aprobaron para recaudar el dinero necesario para pagar las indemnizaciones por daños sufridos durante el conflicto comunero en Toro por defensores de la causa realista. En su defensa, para eximirse de contribuir en dichos repartimientos, alegaron que, cuando los ataques a los realistas que requerían indemnización habían sido perpetrados, ellos se encontraban desplazados fuera de Toro, en la toma de Tordesillas, y con el deán de Burgos, haciendo guerra al conde de Salvatierra ${ }^{36}$. Por otro lado, que Juan Rodríguez de Fonseca era percibido en Toro como persona con importantes intereses políticos en la ciudad lo demuestra el hecho de que durante la revuelta se llevaron a cabo acciones de represalia contra su persona por los comuneros toresanos. En concreto, en 523 el obispo denunció que «en tiempo de las alteraciones» le fueron tomados en Toro 60 ooo mrs., y todavía no había logrado recuperarlos ${ }^{37}$. Por otro lado, en la fase inicial de la rebelión, los comuneros de Toro interceptaron cartas enviadas por este prelado, presumiblemente a vecinos de la ciudad con simpatías realistas. Así se hace constar en una carta que el doctor Valdivieso, que desempeñó el cargo de corregidor de Toro por las autoridades comuneras, dirigió el 25 de octubre a la Junta de Tordesillas, en la que se informaba sobre la interceptación de las referidas cartas, y la prisión preventiva del mensajero que las portaba, hasta que la Junta dispusiese sobre lo que se debía hacer con él $3^{8}$.

\section{EL DESPLIEGUE DE LA AMBICIÓN POLÍTICA DE ALONSO DE FONSECA EN TORO Y SU COMARCA: SU PARTICIPACIÓN EN LAS LUCHAS BANDERIZAS}

Desde los comienzos de su trayectoria, bastante mal conocidos por falta de información documental, Alonso de Fonseca, pese a su condición de clérigo, se afanó por participar activamente en la vida política de Toro y su entorno, conforme a una pauta más bien propia de un laico. Con este objetivo inició en fecha temprana una larga serie de compras de señoríos, tierras y otros bienes, que prolongó hasta

36. AGS, RGS, IV-1524 $\left(2^{\circ}\right)$. Provisión al corregidor de Toro, a petición de Fernando Barbajero, Francisco de la Estrella, Ruy Gómez y García de Soto, vecinos de Toro, por sí y en nombre de otros consortes, criados del obispo de Burgos.

37. AGS, RGS, II-1523. Comisión al corregidor de Toro, a petición de Francisco de Valladolid en nombre de D. Juan Rodríguez Fonseca, arzobispo de Rosana y obispo de Burgos.

38. DANVILA, 1897-1900, II (Se indica el número de orden del volumen dentro de la obra de Danvila, y no el que ocupa en el conjunto de la colección Memorial Histórico Español, en que se incluye), p. 428. 
momentos próximos al de su muerte, la cual ha sido analizada en detalle por Franco Silva, en su monografía ya citada. La primera operación que documenta este autor está fechada en el año I477, y paradójicamente fue una de las de más envergadura que realizó a lo largo de su vida. Adquirió entonces la fortaleza y el señorío jurisdiccional de la villa de Villanueva de Cañedo a un regidor de Toro, Alonso de Valencia, a quien pagó la elevada cuantía de 2200000 mrs. ${ }^{39}$.

Una de las primeras noticias que hemos encontrado sobre su participación en las luchas de poder que tuvieron por escenario esta ciudad nos la proporciona, por vía indirecta, un documento del año I485. Ciertamente no es mucho lo que sabemos sobre el origen y desarrollo de dichos conflictos, por falta de estudios monográficos dedicados al análisis de esta problemática en Toro. El trabajo pionero que Moreno Núñez dedicó al estudio del regimiento en esta ciudad durante el siglo $\mathrm{XV}$ ofrece un panorama muy general, sin profundizar en el análisis concreto de la lucha política por el control del poder local ${ }^{40}$. Se limita este autor a constatar la importancia que en el grupo oligárquico toresano tuvieron las familias nobles de origen portugués, dedicando incluso un breve estudio monográfico al linaje de los Portocarrero, que también tuvo implantación en otras regiones de Castilla ${ }^{41}$. De los trabajos de Moreno Núñez se puede deducir, sin embargo, que Toro se diferenció en esta etapa de otras ciudades realengas próximas, tales como Ciudad Rodrigo o Salamanca, por el hecho de que no se llegó a implantar allí un procedimiento de reparto institucionalizado del poder local basado en un mecanismo dual de bandos-linaje, que agrupasen a las familias de la oligarquía caballeresca ${ }^{42}$. Tampoco se ha llegado a demostrar por ningún autor que en Toro hubiese arraigado durante el reinado de los Reyes Católicos un conflicto banderizo entre facciones tan bien definidas como las que se disputaron la hegemonía en Plasencia en esta época, tras la reincorporación de la ciudad al realengo, después de haber estado sometida durante unas décadas al señorío de los poderosos Estúñiga, que finalmente fueron obligados por los reyes a renunciar a él ${ }^{43}$.

La documentación conservada, pese a su carácter fragmentario, no deja, sin embargo, lugar a dudas sobre el hecho de que también Toro fue escenario durante el reinado de los Reyes Católicos de enconados enfrentamientos entre familias de la oligarquía noble alineadas en facciones, que hicieron necesaria la intervención con propósitos pacificadores de la Monarquía y de sus delegados los corregidores. Se otorgaron cartas de seguro, y se dieron órdenes de destierro, para evitar que se desatase el recurso a la violencia que llevase al derramamiento de sangre. Varios documentos prueban que uno de los miembros de la oligarquía de Toro de fines

39. FRANCO, 2010, p. 571

40. MORENO, 1985 .

41. MORENO, 1989 .

42. Sobre los procedimientos de reparto ordenado de oficios entre linajes y los enfrentamientos banderizos en Ciudad Rodrigo BernaL, 1989 y Monsalvo, 2009a. Sobre Salamanca, LóPEZ, 1983 y MonSALVo, $2009 b$.

43. DIAGO, 2006 y 2017. 
del siglo XV y comienzos del siglo XVI que estuvo más implicado en enfrentamientos banderizos fue el regidor Juan Rodríguez de Fonseca, que lo era desde I489, fecha en la que pasó a cubrir la vacante surgida por muerte de su hermano Cristóbal de Fonseca ${ }^{44}$. Por la enemistad existente entre él y el regidor Juan de Deza, el corregidor, licenciado Francisco Muñoz, impuso tregua entre ambos, sus hijos, parientes, criados y valedores. El origen del problema había estado en que en una reunión de consistorio, Juan de Deza había pronunciado algunas palabras escandalosas contra Juan Rodríguez de Fonseca. Por esta razón Juan de Deza había sido encarcelado por el corregidor en su casa, pero apeló de dicha decisión ante el Consejo Real, que, después de realizadas las pertinentes pesquisas, lo encontró inocente, poniéndolo en libertad ${ }^{45}$. Para evitar un rebrote del enfrentamiento se les impuso a los dos regidores una tregua por diez años. Pero no se apresuraron a observarla, pues pocos meses después se dirigió una nueva provisión al nuevo corregidor de Toro, licenciado Pedro de la Cuba, apremiándole a que asegurase el cumplimiento de lo dispuesto por su predecesor, y ordenase además el establecimiento de otra tregua entre Juan de Deza y Sancho de Fonseca, hermano de Juan Rodríguez de Fonseca ${ }^{46}$. En cualquier caso las relaciones políticas de este último con este corregidor fueron extremadamente tensas, hasta el punto de que el regidor llegó a presentar contra él una denuncia ante el Consejo Real, acusándole de haber sido «muy odioso y sospechoso en sus pleitos y causas», mostrándose en contrapartida «muy favorable a los que contra él tienen pleitos y querellas civiles y criminales» ${ }^{47}$. En la misma línea se ha de interpretar la denuncia que Juan Rodríguez de Fonseca presentó contra el licenciado Pedro de la Cuba, acusándole de haber abierto las cartas que aquél había enviado desde Valladolid a su mayordomo, Rodrigo de la Serna, quien estaba al cargo de la administración de su hacienda. Para ello había recurrido al uso de la fuerza y las amenazas contra el mensajero que llevaba las cartas, obligándole finalmente a entregarlas contra su voluntad, de modo que el corregidor logró abrirlas y leer su contenido ${ }^{48}$.

Son muchos los aspectos de este conflicto banderizo protagonizado por el regidor Juan Rodríguez de Fonseca de los que no estamos bien informados. Por ejemplo, no hemos podido determinar qué tipo de relaciones políticas mantenía con el obispo Alonso de Fonseca. Hemos querido referirnos con detalle al mismo, no obstante, porque demuestra el arraigo de las luchas banderizas entre familias de la oligarquía caballeresca en Toro durante el reinado de los Reyes Católicos, pese a no haberse detectado por la historiografía la consolidación de bandos bien

44. AGS, RGS, IV-1489, fol. 38. Merced de oficio de regidor de Toro a Juan Rodríguez de Fonseca, contino.

45. AGS, RGS, VIII-1498, fol. 130.

46. AGS, RGS, XII-1498, fol. 266.

47. AGS, RGS, VIII-1499, fol. 170. Provisión al licenciado Pedro de la Cuba, corregidor de Toro, y a su alcalde, para que tomen acompañado en los pleitos que sigue el regidor Juan Rodríguez de Fonseca.

48. AGS, RGS, VII-1499, fol. 378. 
definidos en esta ciudad, similares a los de ciudades próximas como Salamanca o Ciudad Rodrigo.

Pero hay un aspecto de estas luchas banderizas sobre el que nos interesa aquí poner el acento, que justifica que nos detengamos en su análisis. Nos referimos a la directa participación en ellas de Alonso de Fonseca, a pesar de su condición de eclesiástico, que, por otra parte, ocupó sedes episcopales que no tenían ninguna relación directa con Toro. Efectivamente, nuestro protagonista no tuvo inconveniente en intervenir en los asuntos políticos de esta ciudad, pese a que no ocupaba ningún cargo eclesiástico de relevancia en la misma, que, además, no era capital de diócesis.

Que fue un eclesiástico con un régimen de vida propio de un laico queda demostrado por la extraordinaria dimensión que llegó a alcanzar su clientela. Así, en su testamento del año 1505 incluyó legados a más de cuarenta criados ${ }^{49}$. Nada tiene de sorprendente, por consiguiente, que desde fechas tempranas lo encontremos implicado en algunas de las luchas de facciones que tuvieron por escenario Toro. Por ejemplo, en I485 Juan de Ulloa, Jerónimo de Valdivieso y Alonso de Deza el mozo, regidores de esta ciudad, junto con el procurador de la misma, Juan de Morales, denunciaron ante el Consejo Real al corregidor Pedro Gómez Manrique por haber decretado su destierro de la ciudad, conminándoles a que compareciesen en la Corte. Según el corregidor, los mencionados oficiales se habían juntado con el obispo de Ávila, que era entonces Alonso de Fonseca, favoreciéndole contra el propio corregidor y sus oficiales, «a fin de lo complacer» ${ }^{\circ}$. No informa el documento, sin embargo, sobre los motivos por los que Alonso de Fonseca se encontraba en aquellos momentos enfrentado al corregidor.

Poco tiempo después de este incidente se desencadenó un singular proceso que abunda en poner de relieve su incansable afán por reforzar su posición política en Toro y su comarca. Su análisis pormenorizado resulta además de sumo interés porque demuestra que hizo un uso impropio de sus beneficios eclesiásticos con fines políticos, persiguiendo ante todo el medro personal en el ámbito local de donde procedía. Antes de entrar en el estudio de dicho proceso es necesario, sin embargo, que nos detengamos en dar cuenta de la faceta de Alonso de Fonseca como abad comendatario de establecimientos monásticos.

49. FRANCO, 2010, p. 582.

50. AGS, RGS, IX-1485, fol. 131. 


\section{MONASTERIOS EN ENCOMIENDA DE OBISPOS: LOS CASOS DE ALONSO DE FONSECA Y JUAN RODRÍGUEZ DE FONSECA}

En efecto, Alonso de Fonseca, como muchos otros eclesiásticos de alto rango de su época, no se contentó con ejercer como obispo, sino que simultáneamente obtuvo otros beneficios, que prioritariamente le proporcionaban rentas, pero que también podían ser utilizados como fuente de poder político. Entre tales beneficios merecen una mención especial las llamadas abadías comendatarias de monasterios de las más diversas órdenes, que eran concedidas en régimen de administración a miembros del clero secular, que de este modo desplazaban a los abades o priores designados en el seno de las comunidades monásticas de clérigos regulares para presidirlas, inicialmente con carácter vitalicio. Muchos abades comendatarios fueron eclesiásticos de alto rango residentes en Roma, y que sólo estaban interesados en los monasterios que teóricamente tenían a su cargo como administradores para percibir las rentas anexas a sus abadías.

Alonso de Fonseca, siendo obispo, ocupó también el cargo de abad comendatario, al menos de dos casas, ninguna de las cuales estuvo ubicada en alguna de las diócesis de las que fue sucesivamente titular a lo largo de su vida. Se trata por un lado de una comunidad de monjes benedictinos de San Román de Hornija, villa cercana a la ciudad de Toro, y por otro de una comunidad de clérigos regulares de San Agustín en el lugar segoviano de Párraces ${ }^{51}$.

Por lo que respecta a la abadía segoviana, no hemos podido determinar las circunstancias concretas en que se convirtió en abad comendatario de la misma. No habría que descartar que figurase en el lote de la permuta del obispado de Cuenca por el de Osma, acordada con el cardenal de San Jorge, pues según las noticias proporcionadas por Tarsicio de Azcona, este último fue abad comendatario de Párraces ${ }^{52}$. Dicha abadía le proporcionó saneadas rentas en su etapa como obispo de Osma, pues nos consta que en una ocasión dio a renta a Sancho del Espinar, vecino de Segovia, todos los frutos, diezmos, pechos, derechos y posesiones de la misma, de los años 1498 y siguientes por $365000 \mathrm{mrs}$. cada año ${ }^{53}$. No parece probable que la frecuentase mucho, pero consta que estuvo presente en ella el día uno de octubre de 1505 , semanas antes de su muerte. Por otro lado también estableció ciertos vínculos con algunos de los canónigos, incorporándolos a su extenso grupo clientelar. Lo deducimos del hecho de que cuando en una ocasión inició pleito ante el corregidor de Soria contra un hombre de negocios vecino

51. Sobre esta comunidad, que en tiempos de Felipe II dejó de albergar a canónigos regulares, que fueron sustituidos por jerónimos, al tiempo que se vinculaba al monasterio de San Lorenzo del Escorial, de esa misma Orden, Vid. Cueto, 1985 y Gavilán, 1986.

52. AzCONA, 1960, pp. 109-110.

53. AChV, RE, C. 202, X 1505 . 
de esta ciudad, el bachiller Alonso Rodríguez, con el que el obispo mantenía diferencias sobre el arrendamiento que le había efectuado de sus pontificales, en la presentación de la demanda de ejecución le representó como procurador el bachiller Luis Gómez, canónigo de Santa María de Párraces ${ }^{54}$.

Tras su muerte, por otro lado, la vinculación del linaje Fonseca con esta abadía de canónigos regulares continuó, pues su primo, el obispo Juan Rodríguez de Fonseca, pasó a ocupar el puesto de administrador comendatario que había quedado vacante, el cual conservó hasta el final de su vida. Ya lo era en I5Io cuando tuvo lugar un conflicto con algunos de los canónigos, sobre el que los autores que han hecho referencia a él han proporcionado informaciones contradictorias, cuando no erróneas. El más desacertado es Ronald Cueto, quien remitiéndose al padre Sigüenza, recoge la noticia de que en i5ı Alonso de Fonseca, obispo de Osma, y después de Palencia, conde de Pernia, como administrador perpetuo de la abadía de Párraces, viendo la poca observancia de los canónigos quiso poner remedio, incorporando la abadía a la Orden de San Jerónimo, y para ello envió a Párraces, para iniciar los trámites, a fray Sancho de Soria. Algunos canónigos se habría resistido violentamente a admitir la visita de este último, llevando su resistencia hasta el extremo de abandonar la abadía sin licencia para acogerse en el cercano priorato de Santo Tomé del Puerto, también de canónigos regulares de San Agustín 55 . Evidentemente Alonso de Fonseca no era obispo de Osma en I5IO, pues ya había muerto en diciembre de 1505, ni tampoco llegó a serlo nunca de Palencia. Sí lo fue por el contrario su primo Juan Rodríguez de Fonseca, que es el que tendría la administración de la abadía aquel año, y se enfrentó con algunos canónigos rebeldes que buscaron refugio en el referido priorato de Santo Tomé del Puerto, según noticia proporcionada por Cooper ${ }^{56}$. Que estos desórdenes tuviesen algo que ver con un proyecto auspiciado por el obispo Juan Rodríguez de Fonseca de sustituir los canónigos regulares de San Agustín por jerónimos habría que ponerlo en duda, y de hecho tal sustitución no tuvo lugar hasta el reinado de Felipe II, tras la fundación del monasterio de San Lorenzo del Escorial. Este influyente y ambicioso obispo, por lo demás, continuó siendo abad comendatario de Párraces hasta su muerte, y lo era durante los años de la guerra comunera. Buena prueba de ello la proporciona el ataque que perpetraron en dicha abadía los comuneros segovianos, que en represalia por el incendio de Medina del Campo, del que fue principal responsable el hermano del obispo, Antonio de Fonseca, saquearon el edificio monástico, en el que se almacenaban ıo ooo fanegas de cebada, trigo y centeno, por las que después de Villalar la ciudad y Tierra de Segovia fue condenada a ofrecer restitución y compensación ${ }^{57}$.

\footnotetext{
54. AChV, RE, C. 196 (XII-1504).

55. CUeto, 1985 , pp. 23-24.

56. COOPER, 1991, vol. II, p. 1.159

57. SZÁSZDI, 2009.
} 
El hecho de que Juan Rodríguez de Fonseca fuese el sustituto de su primo Alonso de Fonseca como abad comendatario de Santa María de Párraces lo consideramos bastante simbólico, y abunda en poner de manifiesto la utilización por este linaje de los beneficios eclesiásticos en su propio provecho, acumulándolos sin freno. No fue, en efecto, la única comunidad monástica que este prelado tuvo en administración para cobrar sus rentas, sino que, desde este punto de vista, superó a su primo, pues tenemos noticia de que al menos lo fue de otras dos, además de Párraces, las dos de enorme prestigio en el panorama monástico castellano. Se trata del monasterio de San Isidoro de León, del que nos consta que en 1523 era perpetuo administrador. En calidad de tal solicitó poder apear el patrimonio perteneciente al monasterio de Nuestra Señora Santa María de la Vega, en Salamanca, que era dependiente del monasterio leonés ${ }^{5}$. Por otro lado, también sabemos que tuvo hasta su muerte la encomienda del monasterio benedictino de San Zoilo de Carrión,como consecuencia de lo cual se puso freno al proceso de incorporación del mismo a la congregación observante de San Benito de Valladolid, que ya se había iniciado con su desvinculación con respecto al monasterio francés de Cluny, del que había sido priorato durante varios siglos. En efecto, según denunciaron los representantes del monasterio de San Benito de Valladolid en I524 ante el rey, mientras vivió el obispo de Burgos, Juan Rodríguez de Fonseca, éste percibió las rentas del monasterio de San Zoilo, pero no atendió a su responsabilidad de mantener en buen estado sus edificios, que estaban en peligro de caerse. Por ello solicitaron que con cargo a los bienes que había dejado el difunto se financiasen las obras de reparación necesarias en San Zoilo ${ }^{59}$.

\section{UTILIZACIÓN POLÍTICA POR ALONSO DE FONSECA DE SU POSICIÓN COMO ABAD COMENDATARIO DE SAN ROMÁN DE HORNIJA}

Para Alonso de Fonseca el monasterio benedictino de San Román de Hornija, aunque aparentemente se encontraba en un estado de grave decadencia a fines del siglo $\mathrm{XV}$, presentaba un evidente interés por el hecho de que se ubicaba muy cerca de su ciudad natal, Toro, y porque, además disfrutaba del señorío jurisdiccional pleno sobre la villa donde estaba ubicado ${ }^{60}$. No fue por casualidad, por tanto, que nuestro protagonista se hizo con el control de dicha comunidad monástica, sino que para ello puso en práctica un bien meditado plan con el objetivo último de reforzar su

58. AGS, RGS, I-1523 Fonseca.

59. AGS, RGS, XII-1524. Provisión dirigida a los testamentarios del difunto obispo de Burgos, Juan Rodríguez de

60. El grueso de las noticias que vamos a proporcionar sobre las actuaciones de Alonso de Fonseca en el monasterio de San Román de Hornija procede de Archivo Histórico Nacional (=AHN), Clero, libro 16.809. 
posición de poder en la comarca de Toro. Lo prueba en concreto el acuerdo al que llegó, siendo obispo de Ávila, con el abad del monasterio leonés de San Pedro de Montes, en virtud del cual le cedió una serie de beneficios eclesiásticos, a cambio de su renuncia a toda pretensión sobre San Román de Hornija. En la bula que en I479 el Papa Sixto IV expidió a favor del obispo de Ávila, haciéndole merced del priorato del monasterio de San Román de Hornija, se reconocía de forma explícita que hacía más de 20 años que el abad de San Pedro de Montes lo poseía, pero era con mal título, por lo que podía considerarse vacante. Consiguientemente el Papa nombró a Alonso de Fonseca como administrador de dicho priorato. Y al cabo de unos pocos años éste comenzó a poner en práctica su plan para utilizar dicha posición de cara a favorecer su medro personal.

Entró en negociación con este objeto con el monasterio observante de San Benito de Valladolid para que el de San Román se incorporase a la Congregación de monasterios benedictinos observantes que la casa vallisoletana con gran esfuerzo estaba poniendo en marcha. Pero no se trató de una decisión que estuviese inspirada exclusiva ni prioritariamente por el afán reformista del obispo Fonseca, ni por su simpatía hacia la forma de vida que los monjes adoptaban en los monasterios observantes. Por el contrario, todo invita a sospechar que la incorporación de San Román a la Congregación observante fue una oportuna excusa de la que se sirvió este ambicioso prelado, que entonces ocupaba la sede de Cuenca, para hacerse con el señorío efectivo de la villa de San Román de Hornija, y de este modo reforzar su posición de poder en la comarca de Toro.

Todo el proceso se inició con la firma de una capitulación y concordia entre Alonso de Fonseca, obispo de Cuenca como comendatario y administrador perpetuo del monasterio de San Román de Hornija, de una parte, y el prior y monjes del monasterio de San Benito de Valladolid, de la otra. Se otorgó el documento en el interior de este último monasterio, el 27 de enero de I489, y en él se proclamaba que el objeto del acuerdo era la «reedificación, reformación y redición a regular observancia» del dicho monasterio de San Román, siempre a condición de que el papa lo aprobase. El obispo justificó su decisión de firmar la concordia con los benedictinos vallisoletanos con el argumento de que el monasterio de San Román de Hornija está «tan disipado y destruido y defetuoso y caresciente así de personas religiosas que en él religiosamente vivan segund su regla y orden, como de los edificios del dicho monasterio y oficios de él, y los ornamentos, cálices y libros y otras cosas necesarias para el culto divino». Por ello, dado que el monasterio no tenía otros bienes adecuados para afrontar las necesidades financieras que de su estado de postración se derivaban, habían llegado a la conclusión de que la solución más viable era la de vender el señorío jurisdiccional que le pertenecía sobre la villa de San Román de Hornija.

En concreto se preveía una completa reconstrucción del edificio monástico, y la adquisición de ornamentos, cálices, libros y otros objetos necesarios para el funcionamiento de la comunidad. En el acuerdo firmado, ambas partes estimaron 
que los gastos que exigía esta empresa ascenderían a 2039536 mrs.. Para asegurar el éxito de la reconstrucción, Alonso de Fonseca se comprometió a que en el caso de que de la venta del señorío de la villa de San Román de Hornija no se obtuviese tal cantidad de dinero, él aportaría de su propio peculio la diferencia. Por otra parte se incluyeron también bastantes cláusulas de garantía para el monasterio, a fin de que la pérdida del señorío jurisdiccional sobre la villa no afectase a su viabilidad económica. En concreto, se dispuso que se le había de permitir disponer de tierras y suelo en término de la villa donde plantar viñas suficientes para obtener una cosecha anual de 2 ooo cántaras de vino.

Según se denunció más adelante por numerosos testigos, la decisión de llevar a cabo la venta del señorío jurisdiccional se tomó a espaldas de los propios monjes de San Román de Hornija, a los que no se consultó antes de solicitar al Papa la necesaria licencia para poder vender. Las diligencias para proceder a la venta también se llevaron a cabo al parecer con todo secretismo, para asegurarse de que fuese el propio Alonso de Fonseca el que se hiciese con la posesión de facto de este señorío. Recurrió para ello a la interposición de un testaferro, su criado Diego de Tapia, que era alcaide de Bonilla, quien compró el lugar y tomó posesión de él secretamente, de noche. Procedió tan en secreto que pocos en la villa se enteraron de la operación. A partir de entonces el que de hecho actuó como señor de la villa, que contaba con más de doscientos vecinos, fue el propio Alonso de Fonseca, a quien se acusó incluso de exigir nuevas prestaciones señoriales a los vecinos, en forma de gallinas, dinero y otras imposiciones.

Paralelamente Alonso de Fonseca puso en marcha las obras de reedificación del monasterio de San Román, al que trató de dotar de unas buenas infraestructuras para su defensa, hasta el punto de que se llegó a denunciar que parecía más fortaleza que casa de religión. Los testigos fueron unánimes al declarar que este prelado, que ocupaba entonces la sede de Cuenca, trataba a los vecinos de San Román de Hornija como si fuesen sus propios vasallos solariegos. La villa, dependiente del señorío jurisdiccional del monasterio benedictino del mismo nombre, había estado en la fase anterior bajo la encomienda del Almirante de Castilla, que concentraba numerosos señoríos en la comarca. A cambio de la protección que como encomendero les garantizaba este poderoso noble habían estado obligados a efectuarle algunas prestaciones, entre las que estaba la entrega de 200 gallinas cada año. A partir del momento en que Alonso de Fonseca se hizo con el control efectivo de la villa prohibió explícitamente a sus vecinos que tuviesen como encomendero al Almirante, y les ordenó que, en adelante, las referidas gallinas se las entregasen a él ${ }^{61}$.

Ante esta situación los reyes decidieron intervenir, logrando que el Papa Inocencio VIIl otorgase una bula que autorizaba a revocar la operación de venta de los derechos

61. Según declaraciones de testigos contenidas en la pesquisa que por orden de los Reyes Católicos llevó a cabo el corregidor de Toro en diciembre de 1490, que se recoge en AHN, Clero, libro 16.809. 
señoriales que sobre la villa de San Román de Hornija poseía el monasterio del mismo nombre. Fueron comisionados para ello dos jueces apostólicos, Pedro López, chantre de Zamora, y Juan de Nolla, canónigo de esta misma catedral y arcediano de Tioneo en la de Oviedo. En octubre de I49I los reyes comisionaron a su criado, Pedro de Ontañón, para que compareciese ante dichos jueces a fin de que se llevasen a cumplimiento las diligencias necesarias para que la venta quedase anulada ${ }^{62}$. Se tomó información a testigos, que confirmaron el carácter fraudulento de la operación, por lo que finalmente los referidos jueces apostólicos pronunciaron sentencia por la que declararon nula la venta.

Pero la intervención de los reyes fue más allá, pues no se conformaron con restablecer el statu quo anterior a la firma del acuerdo con el abad de San Benito de Valladolid, sino que decidieron que fuese la propia Monarquía la que adquiriese al monasterio benedictino los derechos señoriales que poseía. Justificaron la conveniencia de la operación con el argumento de que la dicha villa de San Román de Hornija se localizaba cerca de la ciudad de Toro «y situada en los términos de ella». Es decir, que su objetivo último era incorporar la villa al señorío urbano de esta ciudad, haciendo recaer la obligación de financiar el coste financiero de la operación sobre la propia corporación urbana. Cerraron por ello los monarcas un acuerdo con fray Juan de San Juan, prior de San Benito de Valladolid, que a la vez era prior del monasterio de San Román, por virtud del cual se le abonaría la cuantía de I 53I 980 mrs, que en algunos documentos es redondeada en I 533000 mrs. a cambio de la renuncia a los derechos señoriales que el monasterio poseía sobre la villa donde se ubicaba ${ }^{63}$. Llama la atención que dicha cantidad se sitúa muy por debajo de la contemplada en el primer acuerdo entre los benedictinos de Valladolid y Alonso de Fonseca, que superaba los 2 millones de mrs. No cabe afirmar, por tanto, que la intervención de los reyes resultase en beneficio económico de los monjes benedictinos, sino al contrario. Pero tampoco hay certeza de que Alonso de Fonseca hubiese llegado a abonar efectivamente la cantidad comprometida en el acuerdo inicial con el prior de Valladolid para garantizar la reconstrucción de San Román de Hornija, que superaba los dos millones de mrs. Por otra parte, además de rebajarse la cantidad en que se valoraban los derechos jurisdiccionales objeto de transacción, el pago de la cantidad comprometida se efectuó con evidentes dificultades y retrasos. De hecho la mayor parte del precio, en concreto un millón de mrs, había de ser satisfecho por la propia ciudad de Toro, a cambio del privilegio de poder incorporar a su jurisdicción la villa objeto de compra. El resto no queda muy claro en los documentos consultados quién lo debería pagar, aunque aparentemente corrió a cargo de la Real Hacienda.

62. AGS, RGS, X-1491, fol. 230. Provisión expedida en la Vega de Granada, 13-X-1491.

63. Según provisión de los Reyes Católicos, en AGS, RGS, VI-1494, fol. 7. 
Los documentos prueban que el concejo de Toro no fue puntual a la hora de abonar el millón de mrs. con que le obligaron los reyes a contribuir en la operación. Así, en una real cédula de i50 i se recogía la denuncia por parte del monasterio de San Román de Hornija de que aún no había terminado de ingresar el precio estipulado en el contrato de venta, sino que restaban 150 ooo mrs. pendientes de pago, por lo cual ese mismo año los reyes conminaron al corregidor de Toro para que inmediatamente se abonase dicha cantidad a los monjes ${ }^{64}$. Por otro lado, los propios reyes estuvieron dando en los años 1500 y 1503 órdenes a los contadores mayores para que se librasen en fondos ciertos al monasterio de San Benito de Valladolid las cantidades que quedaban pendientes por la venta de la villa de San Román de Hornija ${ }^{65}$. Esto prueba que la Real Hacienda se implicó en el proceso de pago, y que varios años después de cerrarse la operación los benedictinos todavía no habían cobrado el precio estipulado en su integridad.

De todo este complejo proceso nos interesa aquí destacar que en esta ocasión la Monarquía puso freno a las ambiciones políticas de Alonso de Fonseca, inmiscuyéndose en los asuntos internos de la Orden benedictina. Lo hizo en concreto dando al traste con un acuerdo que este prelado, que era a la vez administrador comendatario de un pequeño monasterio benedictino próximo a Toro, había cerrado con los propios benedictinos observantes de Valladolid, que con la excusa de propiciar la reforma y reconstrucción de una comunidad monástica arruinada, iba en última instancia orientado al reforzamiento de la posición política de Alonso de Fonseca en la comarca de su ciudad natal.

La intervención de los reyes en este proceso favoreció, sin duda, a la ciudad de Toro como comunidad política, pues reforzó su posición como «señor de vasallos», al incorporar la villa de San Román de Hornija, rebajada a la condición de aldea, al territorio sobre el que la corporación urbana ejercía jurisdicción. Pero se ha de resaltar que no fue una decisión aplaudida por la sociedad política toresana en su integridad. A este respecto resulta muy reveladora una provisión que en septiembre de 1494 dirigieron los reyes al corregidor de Toro, bachiller Diego Fernández de San Millán ${ }^{66}$. En ella se hace constar que Pedro de Monroy en nombre de la ciudad de Toro había denunciado ante el Consejo Real que después de haberse decidido la incorporación de la villa de San Román de Hornija a la jurisdicción de Toro:

por parte de algunos vecinos y regidores de la dicha villa que solían vivir mal en los tiempos pasados, y mandar la dicha villa teniendo las varas y la gobernación de la justicia de ella, se han puesto y pusieron contra nuestros mandamientos, diciendo que si la dicha ciudad fuese a tener la posesión y propiedad de la dicha villa, que ellos la impedirían y resistirían con mano armada, y que no la consentirían tomar.

64. AGS, RGS, IX-1501, fol. 27. Provisión de Granada, 2-IX-1501, al corregidor de Toro, en que se inserta cédula de Granada, 20-III-1501.

65. AGS, Cámara Castilla, Cédulas, 4,68, 1. Sevilla, 30-IV-1500. Y Cédulas, 6, 58, 2. Alcalá de Henares, 8-1I-1503.

66. AGS, RGS, IX-1494, fol. 313 . 
No parece demasiado arriesgado aventurar que detrás de este sector de la sociedad política local que se oponía a la incorporación de San Román de Hornija a la Tierra de Toro estaba el obispo Alonso de Fonseca, el gran perjudicado por el fracaso de la operación contemplada en el primer acuerdo con los benedictinos observantes de Valladolid, que le había facilitado a él el control de dicha villa para convertirla en un baluarte de su poder personal. Por otro lado, esta denuncia confirma sin ningún género de dudas que la sociedad política toresana se encontraba dividida durante el reinado de los Reyes Católicos en irreconciliables facciones. Lamentablemente no conocemos con detalle la composición de las mismas, ni las razones por las que surgieron. Que Alonso de Fonseca, ya desde su etapa como obispo de Ávila, estuvo plenamente integrado en una de ellas es un hecho que se deduce de varios significativos testimonios. Así tendremos ocasión de comprobarlo al dar cuenta a continuación de los sucesos violentos que empañaron la vida política de esta ciudad realenga en el tránsito del siglo XV al siglo XVI, y del papel desempeñado en ellos por el obispo Fonseca y su familia.

\section{ALTIBAJOS EN EL PROYECTO DE CREACIÓN DE UN GRAN ESTADO SEÑORIAL PARA SU HIJO BASTARDO GUTIERRE}

El fracaso de su proyecto de hacerse con el control de la villa de San Román de Hornija no disuadió a Alonso de Fonseca de continuar alimentando grandes ambiciones para su engrandecimiento personal y el de su familia en Toro y su comarca. A este respecto sea de resaltar que el principal móvil que inspiró sus actuaciones fue conseguir para su hijo bastardo Gutierre de Fonseca una sólida posición política en su ciudad de origen.

Durante el período en que ocupó la sede de Ávila, Alonso de Fonseca tuvo con una mujer llamada Teresa de las Cuevas al menos tres hijos bastardos, pese a su condición de eclesiástico obligado al voto de castidad. Dos de ellos fueron varones, y una tercera, llamada Isabel, hembra. Todos ellos fueron legitimados mediante privilegios concedidos por los Reyes Católicos en el transcurso de la década de I490. En concreto Gutierre fue legitimado por cédula fechada en Santa $\mathrm{Fe}, 2 \mathrm{O}-\mathrm{V}-\mathrm{I} 492^{67}$. Y en esa misma fecha el obispo, que entonces ocupaba la sede de Cuenca, hizo donación inter-vivos de un importante patrimonio que había ido reuniendo mediante compras en los años previos a favor de este retoño. Por su parte, su hermana Isabel tuvo que esperar unos cuantos años para recibir idéntico privilegio de legitimación de estos mismos monarcas, en concreto hasta $1499^{68}$. Por

67. AGS, RGS, V-1492, fol. 71. Legitimación de Gutierre de Fonseca, hijo de Alonso de Fonseca, obispo de Cuenca, habido mientras era obispo de Ávila en Teresa de las Cuevas.

68. AGS, RGS, V-1499, fol. 117. Legitimación de Isabel Fonseca. 
referencias indirectas tenemos noticia de la existencia de un tercer hijo bastardo, llamado Fernando de Fonseca, para el que el obispo, su padre, también obtuvo privilegio de legitimación, el cual fue destinado a la carrera eclesiástica, aunque carecemos de detalles sobre su trayectoria ${ }^{69}$.

El interés por asegurar una sólida posición política a uno de estos tres hijos, Gutierre, explica que Alonso de Fonseca no cesase en el empeño por tomar parte activa en la vida política de Toro durante todo el reinado de Isabel la Católica. Las intenciones que abrigaba respecto a este hijo quedaron bien puestas de relieve cuando el 20 de mayo de I492, siendo todavía obispo de Cuenca, otorgó una generosa donación a su favor de un importante conjunto de bienes, adquiridos en las décadas previas, y que en su mayor parte se ubicaban en el entorno de la ciudad de Toro. En el documento hizo mención expresa a las villas de Villalbarba y Villafelis, y heredamientos en los lugares de Barrales y Guarrate, en jurisdicción de Toro, Villanueva del Cañedo con su fortaleza y jurisdicción, los lugares de Cardeñosa, Huelamos y Santinanes, en jurisdicción de Salamanca, las casas principales en que habitaba en la ciudad de Toro, y todos los mrs. de juro que poseía ${ }^{70}$.

Entre los indicios de su involucramiento en las luchas por el poder en Toro, siempre con la vista puesta en la promoción de su hijo, cabe destacar algunas solicitudes de cartas de seguro por vecinos de esta ciudad, como Alonso de Cazorla, a quien le fue concedida una en I498, porque había transmitido a los reyes su temor a previsibles ataques del obispo ${ }^{71}$. Por otro lado son varios los indicios aportados por la documentación que llevan a concluir que este prelado, pese a su condición de eclesiástico que le vedaba el recurso al uso de la fuerza, tuvo una cierta predisposición hacia los comportamientos violentos. Así, además de vecinos de Toro, otros varios individuos de muy diversa procedencia solicitaron cartas de seguro para ponerse a salvo de sus ataques. En la mayoría de los casos se trata de clérigos. Así, en 1499 ocho beneficiados en diversas parroquias del obispado de Osma solicitaron carta de seguro porque se temían de él, sus provisores, hombres, criados, parientes y vasallos ${ }^{72}$. Ese mismo año se expidió otra carta de seguro a favor de varios clérigos ${ }^{73}$, y otra a favor de dos hermanos vecinos de la ciudad de Calahorra, de los que desconocemos la relación que tenían con él74. Pocos años después les tocó el turno de solicitar carta de seguro a algunos de sus vasallos, vecinos de lugares del señorío de la mitra de Osma, en concreto a los vecinos del

69. Así se hace constar en una cédula expedida por el rey en Segovia, 7-VIII-1505, autorizando al obispo Alonso de Fonseca a fundar mayorazgo en favor de Gutierre de Fonseca.

70. Este documento, fechado en Pareja, 20-V-1492, se inserta en AGS, RGS, VII-1501, fol. 89.

71. AGS, RGS, II-1498, fol. 153 .

72. AGS, RGS, IX-1499, fol. 468. Carta de seguro a favor de Pedro de Magaña, cura de Pozalmuro y Torrubia, doctor Alvar Alfonso, cura de Canales, doctor García de Ágreda, cura de Almenar, doctor Antonio de Contreras, cura de Caravantes, Miguel Pérez de Pinilla, Pedro Gómez de Hinojosa del Campo, Pedro Sánchez del Villar y Diego Garcés, cura de Peroniel y Noviercas.

73. AGS, RGS, IX-1499, fol. 19.

74. AGS, RGS, X-1499, fol. 71. Carta de seguro para Juan y Catalina Jiménez, hermanos vecinos de Calahorra. 
arrabal de la villa de Ucero ${ }^{75}$. Pero en este caso la hostilidad era consecuencia de haberse desarrollado una enconada rivalidad entre los vecinos del arrabal y los de la villa, ubicada en un risco alejado de los caminos. Por ello, por ser lugar de más tránsito, se habían abierto en el arrabal una panadería y una taberna para viandantes y para los propios vecinos del arrabal, para no tener que subir a la villa. Pero éstos se quejaron porque los alcaldes se lo prohibían, atendiendo órdenes del provisor de Osma ${ }^{76}$.

\section{EL EPISODIO DEL HOMICIDIO DEL REGIDOR Y ALCAIDE DE TORO JUAN VÁZQUEZ}

Volviendo al análisis de la participación de Alonso de Fonseca en su etapa como obispo de Osma en la vida política de Toro, interesa detenerse en dar cuenta de un cruento episodio que la empañó a comienzos del año I500. Desconocemos bastantes detalles sobre el contexto en se enmarca dicho suceso, y las motivaciones de los implicados en el mismo. Se trata del asesinato del alcaide de la fortaleza de la ciudad y regidor, Juan Vázquez, que fue perpetrado por el hijo bastardo del obispo, Gutierre, auxiliado por sus criados y otras personas de su facción. A raíz de ello los Reyes Católicos en febrero de 1500 expidieron una provisión dirigida al propio obispo de Osma y a Fernando de Fonseca, ordenándoles que saliesen de forma inmediata de la ciudad de Toro y sus términos, y no volviesen a entrar hasta que se les autorizase mediante licencia real. La razón esgrimida era que de su presencia dentro de la ciudad se podían recrecer escándalos e inconvenientes, como consecuencia del reciente suceso de la muerte del alcaide ${ }^{77}$. Es una buena prueba de que al obispo no se le consideraba exento de responsabilidad en las actuaciones de su hijo bastardo, con el que haría causa común. Al poco tiempo, en marzo de I500, los monarcas expedían otra provisión dirigida a los alcaldes de Casa y Corte para que apresasen los cuerpos de Gutierre de Fonseca y otros vecinos de Toro que habían participado en el mencionado asesinato, los cuales se habían dado a la fuga, contando con el apoyo de otros vecinos que les proporcionaron favor y ayuda ${ }^{78}$. Hubo entre ellos incluso varias mujeres, las cuales, después de que se hubiesen refugiado en una iglesia de Toro para escapar a la acción de la justicia, les habían metido armas y bastimentos ${ }^{79}$.

Paralelamente se decidió el envío como juez pesquisidor del comendador Fernando de Gamarra, para que tomase información sobre lo sucedido y actuase

75. AGS, RGS, III-1501. Carta de seguro a los vecinos del arrabal de Ucero.

76. AGS, RGS, III-1501. Comisión al corregidor de Aranda.

77. AGS, RGS, II-1500, fol. 175 .

78. AGS, RGS, III-1500,

79. AGS, RGS, I-1501, fol. 304. Las acusadas de haber ayudado a Gutierre de Fonseca y los otros que habían participado con él en el homicidio fueron Ana Rodríguez, Isabel Andina y Leonor, hija de María de Olmos. 
contra los que encontrase culpables. Este juez ordenó el secuestro de un importante conjunto de bienes, entre los que destacaba la villa de Villanueva de Cañedo con su fortaleza y jurisdicción, que coinciden con los que en mayo de 1492 había donado Alonso de Fonseca, entonces obispo de Cuenca, a su hijo Gutierre. De igual modo ordenó el secuestro de las rentas generadas por la explotación de este patrimonio, entre las que destacaba una gran cantidad de cereal acumulado de varios años, y repartido entre diversos silos ${ }^{80}$.

El obispo reaccionó, sin embargo, frente a estas medidas de forma inmediata, denunciando su ilegalidad. Alegó que los bienes secuestrados no eran propiedad de su hijo, sino suyos propios. De este modo negaba validez a la donación inter vivos que le había realizado en Pareja en I492. Y ciertamente en dicha donación se había incluido una cláusula que resultó decisiva para que por vía de justicia se le diese la razón, poniendo a salvo del embargo y la posterior confiscación el patrimonio trabajosamente reunido para su hijo. Dicha cláusula preveía la anulación de la donación en caso de la comisión de algún crimen que conllevase la confiscación de su hacienda por el beneficiario de la misma. Por este motivo, en un plazo de tiempo sorprendentemente breve el Consejo Real expidió ejecutoria a favor del obispo de Osma en julio de I50I, y contraria a las demandas interpuestas por los herederos del asesinado alcaide de Toro $^{81}$, que anuló de forma abrupta las consecuencias económicas del homicidio para el linaje Fonseca.

Después de la expedición de las ejecutorias de i50i que tocaban a la confiscación del patrimonio, el calvario judicial de Gutierre de Fonseca, son embargo, no acabó, ante el empeño de los herederos del alcaide por hacerle pagar por su crimen. No hemos podido reconstruir en detalle los pormenores del proceso judicial que siguió su curso. Sí nos ha llamado la atención advertir que, en defensa de su causa, el obispo y su hijo no dudaron en recurrir a sus conexiones eclesiásticas para enfrentarse a una Monarquía a la que en última instancia ambos tanto debían. Así, sorprende que, en la prosecución de su defensa, los Fonseca provocaron un grave conflicto de competencias jurisdiccionales entre la Monarquía castellana y la Iglesia, que obligó a Isabel la Católica a movilizar incluso a su embajador en Roma, Juan de Rojas. La reina le dirigió, en efecto, una cédula desde Alcalá de Henares en mayo de 1503, haciéndole partícipe de una queja presentada por la viuda del alcaide asesinado. Según ésta, Gutierre de Fonseca había obtenido, «con relación no verdadera», un rescripto del Papa dirigido a varios clérigos del reino de Portugal, de las diócesis de Coimbra y Braga, que como jueces apostólicos la habían emplazado a ella y demás herederos del alcaide para que compareciesen

80. AGS, RGS, V-1501, fol. 317. Provisión a Diego de la Fuente y Alonso Ruiz, vecinos de Toro, y Alonso regidor, vecino de Guarrate, y Francisco de las Osas, habitante en Villanueva de Cañedo. En su poder estaba depositado el cereal que el obispo tenía «ensilado y entrojado», el cual se estaba estropeando y en peligro de perderse, como consecuencia del embargo decretado por el comendador Gamarra.

81. AGS, RGS, VII-1501, fol. 89. 
ante ellos en la ciudad portuguesa de Miranda, para tomarles declaración en relación con la acusación de asesinato presentada contra Gutierre de Fonseca. Era toda una afrenta para la jurisdicción civil de la Monarquía castellana, no sólo por la interferencia que suponía de la jurisdicción eclesiástica en un asunto que no le competía, sino por la circunstancia agravante de que sus súbditos fuesen citados a comparecer en otro reino, el de Portugal, para declarar sobre un delito cometido en el reino de Castilla ${ }^{82}$.

Pese a estas graves tensiones, que continuaban en plena efervescencia en las vísperas de la muerte de la Reina Católica, la Monarquía, que en un primer momento había aparentado mostrar tanto rigor, propiciando un castigo ejemplar para Gutierre de Fonseca, por la gravedad de su crimen, terminó cediendo en todos los terrenos. En consecuencia el asesinato del alcaide de Toro quedó en la práctica impune, mientras que Gutierre lograba una plena rehabilitación, sin recibir ningún castigo.

El patrimonio del obispo de Osma no sólo fue salvado del embargo con el argumento de que no era propio de Gutierre de Fonseca, sino que muy poco tiempo después, habiendo fallecido ya la reina Isabel, se volvió a efectuar una transferencia formal del mismo en su integridad a favor de este hijo bastardo que hacía muy pocos años había cometido un grave acto de homicidio. El obispo, en efecto, tras haber obtenido una real cédula, fechada en Segovia el 8 de agosto de I505, por la que se le autorizaba a fundar mayorazgo a favor de Gutierre, encontrándose de visita en el monasterio de Párraces el ro de octubre de 1505 procedió a la fundación formal del mayorazgo. Incluyó en él los mismos bienes de los que ya le había hecho donación inter vivos en mayo de $1492^{83}$. La declaración de invalidez de dicha donación quedó así desenmascarada como una mera maniobra legal, de la que todos se olvidaron después de la muerte de la reina, para probable disgusto de la viuda y demás herederos del alcaide Juan Vázquez.

\section{LA REHABILITACIÓN DE GUTIERRE DE FONSECA, Y SU PAPEL DURANTE LA GUERRA DE LAS COMUNIDADES}

Pero la falta de castigo a Gutierre de Fonseca por el homicidio que perpetró no sólo se puso en evidencia en esta sorprendente fundación de mayorazgo, sino que su trayectoria política posterior demuestra que no tuvo que afrontar significativas

82. AGS, Cámara-Cédulas, 6, 101,7. Cédula de Alcalá de Henares, 20-V-1503.

83. El documento de fundación de mayorazgo puede consultarse en AGS, Cámara de Castilla, Diversos, leg. 38 , doc. 12. También ha sido publicado, a partir de un documento del archivo de los duques de Alburquerque, por FRANCO, 2010. Los bienes incorporados al mayorazgo fueron en concreto Villanueva de Cañedo, Cardeñosa, Huelmos, y Santibañes y Guarrate,Villalbarba, Villafeliz y Villaster, las aceñas de La Moraleja, en el río Duero, en término de Tordesillas, y los mrs. de juro perpetuo en Toro y en Palencia, heredad de pan llevar en término de Penilla, jurisdicción de Toro, y heredamientos en Barriales, jurisdicción de Toro. Con las casas principales en Toro, «cabe la iglesia mayor de Toro». 
dificultades para consolidarse pronto como uno de los miembros más influyentes del grupo oligárquico de la ciudad de Toro. Se cumplieron así sin problemas las expectativas que en él había puesto su padre.

Este proceso de ascenso político de Gutierre de Fonseca, que se aceleró años después de la muerte de su padre, fue facilitado por los acontecimientos que tuvieron lugar en Castilla durante la guerra de las Comunidades. El hijo bastardo del obispo de Osma destacó, en efecto, como uno de los más comprometidos dirigentes del partido realista en la ciudad de Toro, donde desempeñaba el oficio de regidor, al igual que lo hicieron otros muchos miembros de su familia a lo largo del siglo XV.

Al inclinarse por apoyar al rey Carlos I, Gutierre de Fonseca hizo causa común con sus más célebres parientes del linaje Fonseca. Entre ellos destacan dos primos de su difunto padre, el obispo de Burgos, Juan Rodríguez de Fonseca, y el hermano de éste, el contador mayor Antonio de Fonseca, señor de Coca y Alaejos, dos de los más comprometidos defensores de la causa del rey, y que por ello figuraron entre los más odiados por los rebeldes comuneros ${ }^{84}$. Pero a sus bien conocidos nombres se ha de añadir el del también celebérrimo arzobispo de Santiago, Alonso de Acevedo y Ulloa, que pocos años después de la guerra comunera ascendería a la sede metropolitana de Toledo, tras la muerte del absentista sobrino de Chievres. Este influyente prelado, en efecto, fue quien en la ciudad de Salamanca encabezó la facción que apoyó la causa realista, por oposición a la que les había venido disputando a los Fonseca-Acevedo desde hacía décadas la preeminencia política en la capital universitaria, en la que militaron los Maldonado y otros linajes salmantinos volcados desde el primer momento en apoyo de la rebelión comunera ${ }^{85}$.

El apoyo prestado por el regidor Gutierre de Fonseca a la causa del rey fue reconocido de forma explícita por el cardenal Adriano en una carta que dirigió a Carlos desde Medina de Ríoseco el I7 de octubre de I520. En ella le informaba de que

En Toro hay gran diferencia y an estado para pelear porque Diego de Ulloa dize que se dé poder a la junta generalmente para todo lo que quisieren hazer y aprovando lo que an hecho, y don Gutierre de Fonseca con todos los que le siguen dizen que no se ha de dar el poder antes lo contradizen. Me ha enbiado a ofrecer gente de pie y de cavallo para servicio de Vuestra Majestad» ${ }^{86}$.

De hecho la actitud prorrealista de Gutierre de Fonseca, y su parentesco con el obispo de Burgos y el señor de Coca y Alaejos, terminaron haciendo insostenible su posición en la ciudad de Toro, de la que tuvo que exiliarse, para desde fuera de ella continuar combatiendo en defensa de la causa del rey. Por ello, ya en una misiva de I de noviembre de 1520 dirigida por el cardenal Adriano al rey

84. SZÁSZDI, 2015, pp. 384-390.

85. Sobre la incidencia del conflicto banderizo entre la facción del arzobispo de Santiago, Alonso de Fonseca, y la del doctor Talavera, en el conflicto de las Comunidades en Salamanca, vid. SANTOS, 2002a y 2002b, PeLIZAEUS, 2007 Y MÖLLER, 2018, p. 160.

86. DANVILA, 1897-1900, II, p. 261. 
desde Medina de Ríoseco le recomendaba que agradeciese por carta la actitud demostrada por Gutierre de Fonseca y Juan de Ulloa, entre otros, por su apoyo a la causa realista en Toro ${ }^{87}$.

Pese a la existencia de una influyente y activa facción realista, los rebeldes comuneros terminaron haciéndose con los principales resortes del poder en esta ciudad zamorana, gracias al apoyo prestado a la rebelión por otras varias familias influyentes de su grupo oligárquico. Ciertamente Joseph Pérez admite que en Toro llegó a darse el inusual fenómeno de la coexistencia de dos corregidores, uno designado por el rey y otro por la Junta ${ }^{88}$. Pero se plantean ciertas dudas sobre lo acertado de esta interpretación, puesto que el grueso de la documentación prueba que quienes controlaron el gobierno de la ciudad a fines de 1520 y comienzos de I52I prestaron abiertamente apoyo al obispo de Zamora, Antonio de Acuña, muy activo en la comarca. Y, además, emprendieron acciones de represalia contra Gutierre de Fonseca y otros miembros de la oligarquía que habían apostado por apoyar la causa del rey, tales como Juan de Ulloa o Pedro de Bazán.

Las actuaciones de los comuneros contra Gutierre de Fonseca tuvieron por escenario no sólo la ciudad de Toro, de la que se exilió, evitando así poner en peligro su persona, sino también otros lugares de su comarca donde poseía bienes. Por lo que toca a la ciudad, su mayordomo, Andrés Sánchez, denunció que, por ser criado de Gutierre, le habían apresado los de la Comunidad y le habían causado múltiples agravios $^{89}$. El propio Gutierre acusó a Pedrarias y Francisco Rodríguez, y otros vecinos de Toro, porque le habían mandado tomar 85 cargas de trigo y 55 ooo mrs. en dinero, en represalia por haberse incorporado al ejército realista ${ }^{90}$. Pero la acción de represalia de mayor envergadura de la que fue víctima afectó a un elemento de su patrimonio ubicado en el entorno rural de Toro. Se trata de una casa en Guarrate, en la que guardaba muchos bienes y tapicería, donde residían dos escuderos suyos, encargados de su guarda. En abril de I52I, estos escuderos fueron atacados, acusándolos a voces de «traidores», y la casa fue saqueada «cuando mucha gente de pie y de caballo de Salamanca iban en socorro de Juan de Padilla, al pasar por dicho lugar» ${ }^{\text {II. }}$. Por otro lado sabemos que, entre los comuneros salmantinos con los que Gutierre de Fonseca pleiteó después de Villalar por los daños que le

87. DANVILA, 1897-1900. II, pp. 470-4. Recomienda que a estos dos y a otros varios les escriba, «agradeciéndoles mucho lo que han hecho y hacen en su real servicio».

88. PÉREZ, 2005, pp. 430-1. Sostiene que durante tres meses Toro contó con dos corregidores, el doctor Valdivieso, nombrado por la Junta, que vigilaba por los intereses de la Comunidad, y el antiguo corregidor, Carlos de Guevara, que «trataba de reprimir el ardor militante de sus administrados». Esta situación insólita se habría mantenido hasta el 15 de enero de 1521, cuando Carlos de Guevara tuvo que abandonar Toro bajo amenaza de muerte.

89. AGS, RGS, III-1522. Provisión al corregidor de Toro.

90. AGS, RGS, VI-1521. Provisión al corregidor de Toro.

91. AGS, RGS, XI-1521. Provisión al corregidor de Toro sobre la querella presentada por Gutierre de Fonseca contra Pedro Maldonado Pimentel y otros capitanes comuneros. En otra provisión se añadió la noticia de que la mencionada casa no sólo fue saqueada, sino también quemada AGS, RGS, VI-1523 $\left(2^{\circ}\right)$. Provisión al licenciado Pedro Martínez de Valdés, juez de comisión. 
causaron durante la guerra, figura el comendador Francisco de Gricio ${ }^{92}$. En otras provisiones, por fin, se alude a otra acción violenta perpetrada por los comuneros contra esta misma casa, de la que se hace responsables a otras personas, en concreto a vecinos de Fuente del Saúco, lugar de señorío del obispo de Zamora ${ }^{93}$.

Tras la derrota comunera en Villalar, Gutierre de Fonseca trató de sacar provecho de la nueva situación no sólo exigiendo indemnizaciones por los perjuicios sufridos durante la guerra por los ataques de los rebeldes. También trató de incrementar su patrimonio mediante la adquisición de bienes confiscados a dirigentes comuneros en condiciones favorables, aunque finalmente sin éxito, por la evidente predisposición a la clemencia que terminó mostrando el rey hacia las familias comuneras. Así ocurrió con la hacienda confiscada al comunero salmantino Francisco Maldonado, condenado a muerte y ajusticiado. Poco después de su ejecución, el 20 de septiembre de I52I, su suegro el doctor Hernán Álvarez Abarca compró por 4.000 ducados los bienes de su difunto yerno. Pero la operación se consideró una estafa por las autoridades, y fue anulada. Entonces Gutierre de Fonseca ofreció el reembolso al doctor de la cantidad que había pagado, para entrar a continuación en posesión del patrimonio de Francisco Maldonado, a la espera de la decisión definitiva del rey. Finalmente, no obstante, Rodrigo Arias Maldonado, hijo del ajusticiado, adquirió estos bienes por I5.00o ducados, de los cuales 6 ooo se abonaron a su madre viuda, Ana de Abarca, por lo que le correspondía percibir de su dote ${ }^{94}$. Gutierre de Fonseca fracasó, por lo tanto, en este intento de convertirse en propietario de este importante patrimonio, como había sido su propósito. Pero lo estuvo administrando durante un tiempo. Por ello luego tuvo que seguir largo pleito con la viuda de Francisco Maldonado sobre el reparto de las rentas generadas por el mismo, en particular por las de la villa de El Maderal, de la que eran señores jurisdiccionales los Maldonado ${ }^{95}$.

Pese a este revés, la posición de Gutierre de Fonseca en el seno del grupo oligárquico de Toro quedó muy reforzada tras la derrota de los rebeldes comuneros. Así, pues, su trayectoria demuestra de forma paradigmática que para los miembros de las oligarquías caballerescas castellanas, proclives a recurrir de forma abusiva a la violencia para la consecuención de sus objetivos políticos, las oportunidades de reconciliación con la Monarquía, después de la comisión de graves actos criminales y de desobediencia, no eran irrelevantes. Gutierre de Fonseca, nacido de la unión ilegítima de un obispo de Ávila y una mujer con la que mantuvo relaciones durante varios años, gracias al empeño de su padre había logrado hacerse con un gran patrimonio, integrado por señoríos, tierras y otros diversos bienes, que le

92. AChV, RE, 413-77 (17-II-1529).

93. AGS, RGS, VI-1521. Provisión al corregidor de Toro. Recoge la denuncia de Gutierre de Fonseca, quien denunció que estando él en el ejército del rey en abril de 1521, entraron en una casa y paneras que él poseía en Guarrate, a una legua de Fuente del Saúco, y le tomaron 800 margas de trigo.

94. PÉREZ, 2005, p. 641

95. AChV, RE, 402-36 (4-X-1527). 
aseguraba un lugar preeminente en el seno de la oligarquía de Toro, a la que se incorporó como regidor. Su participación en un grave acto criminal, el asesinato de un oficial del rey, regidor y alcaide de Toro, estuvo a punto de dar al traste con este fulgurante ascenso, pues todo su patrimonio llegó a ser confiscado por disposición de los oficiales de la justicia de la Monarquía.Se trató, sin embargo, de un mero tropiezo transitorio. Su padre logró con éxito en sus últimos años de vida reconducir su carrera, dejándole dotado con un valiosísimo patrimonio. Su comportamiento durante la guerra de las Comunidades, apostando por la facción que terminó triunfando, hizo todo lo demás, muchos años después de la muerte del obispo, ocurrida en I505. Así, pues, uno de los principales paladines de la causa del rey en Toro en I520 y I52I había sido una veintena de años antes un forajido de la justicia, que buscó refugio en una iglesia, perseguido por los oficiales del rey por su participación en el homicidio de uno de los principales representantes del poder monárquico en la ciudad, un regidor y tenente de la fortaleza. Nos encontramos ante una más de las numerosas paradojas con las que nos sorprende el análisis de los hechos de la historia, que obliga al historiador a matizar visiones esquemáticas de los procesos históricos, basadas con frecuencia en la mera asunción de ideas preconcebidas.

\section{CONCLUSIONES}

La reconstrucción de las trayectorias de los eclesiásticos del linaje Fonseca de Toro nos permite profundizar en la percepción de interesantes aspectos de la historia de Castilla en los siglos XV y XVI. Nos lleva a conocer con mayor detalle la suerte de los nobles portugueses que se exiliaron en dicho reino en esta época, como resultado del cambio dinástico que tuvo lugar en Portugal a raíz de la consolidación en el trono de la llamada dinastía de Avis, de hecho una rama bastarda de la casa real portuguesa. En el presente trabajo nos hemos centrado de forma preferente en la figura menos conocida de este singular grupo de eclesiásticos, que nos ha permitido entrar en contacto con una faceta del perfil de los prelados castellanos de la época bastante desatendida por la historiografía. En efecto, en la mayoría de los estudios sobre el papel de los obispos en la vida política castellana se presta atención preferente a su participación en la alta política cortesana. Alonso de Fonseca, por el contrario, concentró en muy mayor medida sus actuaciones en el escenario urbano, buscando su promoción, y sobre todo la de su descendencia, en su ciudad natal, Toro. Hemos podido demostrar que participó en las luchas políticas que se desarrollaron en esta ciudad durante el reinado de los Reyes Católicos como si de un laico se hubiese tratado.

Por este motivo, la reconstrucción de trayectorias como la suya nos debe llevar a matizar las tesis que sobre el alcance de la reforma de la Iglesia castellana, y más en particular de su episcopado y clero secular, durante el reinado de los Reyes 
Católicos han defendido reputados especialistas de historia eclesiástica como Tarsicio de Azcona o García Oro ${ }^{96}$. Ciertamente la figura del cardenal Cisneros, arzobispo de Toledo, puede considerarse excepcional en el panorama europeo del tránsito entre el Medievo y la Modernidad por múltiples motivos, entre los que destaca su origen social relativamente humilde, su incansable actividad reformadora y su enorme peso político, hasta el punto de haber llegado a actuar durante períodos de tiempo ciertamente breves como regente del reino. Su perfil contrasta radicalmente con los que solían dominar en las sedes episcopales de Francia y el Imperio alemán en estos siglos, cuando la sangre noble era requisito sine qua non para tener opciones a ocuparlas, y los propios cabildos catedralicios estaban vedados a los plebeyos, como tuvieron ocasión de comprobar con disgusto familias de poderosos financieros de origen no noble en Augsburgo ${ }^{97}$. Pero el brillo de su figura, y de otras varias que no podemos entrar aquí a enumerar, no nos debe hacer perder de vista que, por contraste, los Reyes Católicos, y tras ellos su nieto Carlos $\mathrm{I}$, también prestaron decidido apoyo a otros prelados de origen noble, que figuraron entre sus principales colaboradores, los cuales en sus actuaciones pastorales poco hicieron por llevar a la práctica los proyectos de reforma eclesiástica atribuidos por los historiadores a la Monarquía castellana, y mucho menos predicando con el ejemplo de una vida personal conducida conforme a los preceptos propiciados por dichos proyectos reformistas. En su política eclesiástica, como en muchos otros aspectos de su política, estos monarcas transigieron con frecuencia, adoptando medidas contradictorias, y toleraron la persistencia de prácticas que nada favorecían la implantación de las reformas. Todo ello por falta de voluntad o de capacidad para llevarlas a sus últimas consecuencias.

96. AzConA, 1960 y García, 1971.

97. Da cuenta del largo pleito entre la familia Fugger, de origen plebeyo, y el cabildo de la catedral de Augsburgo, que se negaba a admitir como canónigo a un miembro de la misma, y fue llevado en apelación hasta Roma, KIESSLING, 1971. 


\section{ANEXO. INFORMACIÓN SOBRE LAS CONEXIONES DE PARENTESCO ENTRE LOS PRINCIPALES ECLESIÁSTICOS DEL LINAJE FONSECA ${ }^{98}$}

I.- Pedro Rodríguez de Fonseca (Otorga testamento en Toro, II-I-I4I9). Casa con Inés Díaz Botello. Padres de:

I.I.- Pedro de Fonseca, Cardenal diácono de Sant Angelo. Muere en Roma en I42I.

I.2.- Juan Rodríguez de Fonseca. Casa con María de Ulloa.

I.3.- Beatriz Rodríguez de Fonseca. Casa con el doctor Juan Alfonso de Ulloa. Padres de:

I.3.I.- Pedro de Ulloa Fonseca. Casado con Isabel Quijada. Padres de:

I.3.I.I.- Alonso de Fonseca, obispo de Ávila, Cuenca y Osma. Muerto en 1505.

I.3.2.- Alonso de Fonseca, obispo de Ávila entre I445 y I454, arzobispo de Sevilla y de Santiago. Murió en I472. Fundó el mayorazgo de Coca y Alaejos, en el que le sucedió su hermano Fernando (I.3.4).

I.3.3.- Catalina de Fonseca. Casada con Diego González de Acevedo. Padres de:

I.3.3.I.- Alonso de Fonseca y Acevedo. Arzobispo de Sevilla, y de Santiago. Patriarca de Alejandría. Muere en I5I2. Padre de un hijo bastardo:

I.3.3.I.I.- Alonso de Fonseca y Ulloa. Arzobispo de Santiago desde I50 5 y arzobispo de Toledo desde 1523. Fundador del Colegio Mayor de Santiago el Cebedeo de Salamanca (Colegio del Arzobispo).

I.3.4.- Fernando de Fonseca y Ulloa. Sucede en el mayorazgo de Coca y Alaejos, fundado por su hermano el arzobispo de Sevilla (I.3.2). Casó primero con María de Avellaneda y Delgadillo, y en segundas nupcias con Teresa de Ayala. Del segundo matrimonio tuvo a:

I.3.4.I.- Antonio de Fonseca, contador mayor, comendador mayor de Calatrava, señor de Coca y Alaejos.

I.3. 4.2.- Juan Rodríguez de Fonseca, obispo de Badajoz, Córdoba, Palencia y Burgos. Nacido en Toro en I45I.

98. Sólo se han incluido las referencias necesarias para identificar a los personajes mencionados en el artículo, por lo que no están incluidos todos los hijos habidos en los distintos matrimonios. 


\section{BIBLIOGRAFÍA}

Alcocer Martínez, Mariano de: Don Juan Rodríguez de Fonseca. Estudio crítico-biográfico, Valladolid, Imprenta de la Casa Social Católica, I926.

Azcona, Tarsicio de: La elección y reforma del episcopado español en tiempo de los Reyes Católicos, Madrid, CSIC, I96o.

Bernal Estévez, Ángel: El concejo de Ciudad Rodrigo y su Tierra durante el siglo XV, Salamanca, Diputación Provincial, I989.

CAÑAS GÁlvez, Francisco de Paula: Burocracia y cancillería en la corte de Juan II de Castilla (I406-I454): Estudio institucional y prosopográfico, Salamanca, Universidad, 2012.

COOPER, Edward: Castillos señoriales en la Corona de Castilla, Valladolid, Junta de Castilla y León, I99I.

Cueto, Ronald: Párraces. Historia de una abadía segoviana, Segovia, Diputación Provincial, 1985.

Danvila y Collado, Manuel: Historia Crítica y Documentada de las Comunidades de Castilla (En Memorial Histórico Español, vols. XXXV-XL), Madrid, Real Academia de la Historia, I897-I900.

Diago Hernando, Máximo: «El cardenal de San Jorge y los hombres de negocios genoveses en Cuenca durante el reinado de los Reyes Católicos», Espacio, Tiempo y Forma. Historia Medieval, Io (1997), pp. I37-I55.

Diago Hernando, Máximo: «Las luchas de bandos como factor determinante del conflicto comunero en Plasencia (I520-I522)», Cuadernos de Historia Moderna, 3I (2006), pp. 63-89.

Diago Hernando, Máximo: «Violencia en las actuaciones políticas del clero catedralicio en Plasencia a fines del siglo XV y comienzos del XVI», Espacio. Tiempo y Forma. Historia Medieval, 30 (2017), pp. 247-272.

DíAz IbÁÑ̃Ez, Jorge: Iglesia, sociedad y poder en Castilla. El obispado de Cuenca en la Edad Media (Siglos XII-XV), Cuenca, 2003.

DíAz lbÁÑ̃EZ, Jorge : «Iglesia, nobleza y poderes urbanos en la Corona de Castilla durante la Baja Edad Media. Una aproximación historiográfica», en Jorge DíAz IBÁÑEz y José Manuel NiETo SoRIA (Coords.), Iglesia, nobleza y poderes urbanos en los reinos cristianos de la Península Ibérica durante la Edad Media, Murcia, Sociedad Española de Estudios Medievales, 20I9, pp.I5-62.

Franco Silva, Alfonso: «El arzobispo de Sevilla Alonso de Fonseca el Viejo. Notas sobre su vida», en Alfonso Franco Silva, Estudios sobre la nobleza y el régimen señorial en Andalucía, Granada, Universidad, 2006, pp. I27-202.

Franco Silva, Alfonso: «Don Alfonso de Fonseca. Un obispo obstinado en crear un patrimonio para su hijo natural», en Franco Silva, Alfonso: El condado de Oropesa y otros estudios de historia medieval, Jaén, Universidad, 20Io, pp. 567-632.

García Oro, José: Cisneros y la reforma del clero español en tiempo de los Reyes Católicos, Madrid, CSIC, I97I.

Gavilán, Enrique: El dominio de Párraces en el siglo XV. Un estudio sobre la sociedad feudal, Valladolid, Junta de Castilla y León, I986.

Giménez Fernández, Manuel: Bartolomé de las Casas. Vol. I, Sevilla, CSIC, I953.

GonZÁlez Nieto, David: «La casa de Alfonso de Fonseca, arzobispo de Sevilla, dimensiones y mantenimiento de una casa arzobispal a mediados del siglo $X V »$, en Francisco de Paula CaÑas Gálvez y José Manuel Nieto Soria (Eds.), Casa y Corte. Ámbitos de poder 
en los reinos hispánicos durante la Baja Edad Media (I230-I5I6), Madrid, La Ergástula, 20I9, pp. 29I-320.

KIESSLING, Rudolf: Bürgerliche Gesellschaft und Kirche in Augsburg im Spätmittelalter, Augsburg, Vissner Verlag, I97I.

Ladero Quesada, Miguel Ângel: Guzmán. La casa ducal de Medina Sidonia en Sevilla y su reino (I282-I52I), Madrid, Dykinson, 2015.

Loperráez CoRvalán, Juan: Descripción histórica del obispado de Osma, Madrid, Turner, I978, 3 vols (Reedición del original del siglo XVIII).

López Benito, Clara Isabel: Bandos nobiliarios en Salamanca al iniciarse la Edad Moderna, Salamanca, Universidad, I983.

Mitre FernándeZ, Emilio: «La emigración de nobles portugueses a Castilla a fines del siglo XIV», Hispania, 26 (I966), pp. 513-525.

Möller Recondo, Claudia: «Con la iglesia hemos topado». El cabildo catedrañlicio, la universidad de Salamanca en las Comunidades de Castilla», en István Szaszdı LEóNBorja (Coord.) Iglesia, eclesiásticos y la revolución comunera, Sahagún, Centro de Estudios Camino de Santiago, 20I8, pp. I5I-I74.

Monsalvo Antón, José María: «Las luchas de bandos en Ciudad Rodrigo durante la época Trastámara», en Ma . Isabel del Val Valdivieso y Pascual Martínez Sopena (Dirs.), Castilla y el mundo feudal. Homenaje al profesor Julio Valdeón. Junta de Castilla y LeónUniversidad de Valladolid, Valladolid, 2009a, vol. Ill, pp. 20I-2I4.

Monsalvo Antón, José María: «Violence between factions in medieval Salamanca. Some problems of interpretation», Imago Temporis. Medium Aevum, 3 (2009b), pp. I39-I70.

Moreno NúÑEZ, José Ignacio: «El regimiento de Toro en el siglo XV», La ciudad hispánica durante los siglos XIII al XVI, Madrid, Universidad Complutense, I985. pp. 773-783.

Moreno NúÑEZ, José Ignacio: «Los Portocarrero de Toro, linaje de ascendencia portuguesa. Su afincamiento y consolidación en Castilla», Actas das II Jornadas Luso-Espanholas de História Medieval, III, Oporto, Universidad, I989, pp. 993-I030.

Olivera Serrano, César: «Un exiliado portugués en Castilla: Pedro Rodríguez de Fonseca (+ I4I9)», en Reglero de la Fuente, Carlos Manuel (ed.): Poder y sociedad en la Baja Edad Media Hispánica: Estudios en homenaje al profesor Luis Vicente Díaz Martín, Valladolid, Universidad, 2002, pp. 495-503.

Olivera Serrano, César: Beatriz de Portugal. La pugna dinástica Avís-Trastámara, Santiago de Compostela, Instituto Padre Sarmiento. CSIC, 2005.

Olivera Serrano, César: «Los exiliados portugueses en la Castilla de los Trastámara: cultura contractual y conflicto dinástico», en François ForONDA y Ana Isabel CARRASCO Manchado (Dirs.), El contrato político en la Corona de Castilla. Cultura y sociedad políticas entre los siglos X al XVI, Madrid, Dykinson, 2008, pp. 323-353.

Olivera Serrano, César: «Las secuelas religiosas de un conflicto dinástico: Portugueses en Castilla en el siglo XV», en Beceiro Pita en Isabel (Dir.): Poder, Piedad y Devoción. Castilla y su entorno. Siglos XII-XV, Madrid, Sílex, 20I4, pp. I6I-I88.

Ollero Pina, José Antonio: «El trueque de sedes de los Fonseca: Sevilla, I460-I464. Un comentario a Alonso de Palencia», Historia. Instituciones. Documentos, 37 (20I0), pp. 2II-282.

Pelizaeus, Ludolf. Dynamik der Macht: Städtischer Widerstand und Konfliktbewältigung im Reich Karls V, Münster, Aschendorff, 2007.

PÉrez, Joseph: La revolución de las Comunidades de Castilla (I520-I52I), Madrid, Siglo XXIRBA, 2005.

Romero Portilla, Paz: Señores de dos reinos: Los portugueses y el gobierno de Castilla en el siglo $X V$, La Coruña, Universidad, 2011. 
Sagarra Gamazo, A. Burgos y el gobierno indiano: La clientela del obispo Fonseca, Burgos, Caja de Ahorros Municipal, 1998.

Santos Burgaleta, Manuel: «Poderes urbanos y Comunidades de Castilla: La Junta de Salamanca a través de sus actas de sesiones (agosto de 1520-abril de 152I)», Salamanca. Revista de Estudios, 48 (2002a), pp. 357-44I.

SANTOS Burgaleta, Manuel: «Extensiones de poder: Una propuesta de análisis en torno a la articulación de los espacios de poder. La valía del doctor Talavera en Salamanca (I475-I52I)», en Jesús Bravo Lozano (Ed.), Espacios de poder: Cortes, ciudades y villas (S. XVI-XVIII), Madrid, 2002b, vol. I, pp. 73-92.

SZÁSZDI LEÓN-BORJA, István: «Juan Rodríguez de Fonseca y los comuneros segovianos» en Monarquía y Revolución. En torno a las Comunidades de Castilla. I Simposio Internacional de Historia Comunera, Valladolid, 2009, pp. 239-257.

SzÁszDI LEÓN-BoRJA, István: «Los conversos, un grupo cosmopolita en la Guerra de las Comunidades de Castilla. La sombra de los hermanos Fonseca», en István SzÁszdi León-Borja, y María Jesús Galende Ruiz (Eds.), Carlos V. Conversos y comuneros. Liber amicorum Joseph Pérez, Sahagún, Centro de Estudios Camino de Santiago, 20I5, pp. 353-398.

Teresa León, T.: «El obispo Don Juan Rodríguez de Fonseca: diplomático, mecenas y ministro de Indias», Hispania Sacra, I3 (I960), pp. 25I-304.

VÁzquez Bertomeu, Mercedes: «El arzobispo don Alonso Il de Fonseca. Notas para su estudio», Cuadernos de Estudios Gallegos, 47/II2 (2000), pp. 87-Ізг. 
Calidad de Revistas

científicas Españolas

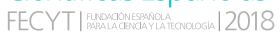

SERIE III HISTORIA MEDIEVAL

REVISTA DE LA FACULTAD DE GEOGRAFİA E HISTORIA
AÑO 2021

ISSN: 0214-9745

E-ISSN 2340-1362

\section{4 \\ issacio. \\ TIEMPO \\ Y FORMA}

\section{Volumen I}

\section{Artículos · Articles}

15 Patricia A. Argüelles Álvarez

Peligros, inseguridades y problemas del viajero visigodo

37 Carmen Barceló, Ana labarta, Josep Benedito \& José M. MELCHOR

Cuatro cerámicas con epigrafía árabe del Museu de Borriana

65 CARlos BARQuero Goñ

Organización de la Orden de San Juan en Castilla durante los siglos XII y XIII

113 Francisco de Paula Cañas Gálvez

Una infanta de Navarra en la corte de Castilla: escenarios políticos en torno a la configuración y evolución del Hostal y la casa de Blanca de Trastámara, Princesa de Asturias (1424-†1464)

\section{David Caramazana Malia}

Las promociones artísticas de Alonso de Ejea, arzobispo y administrador perpetuo de la Archidiócesis de Sevilla y patriarca de Constantinopla (1403-1417)

\section{Pedro Castillo Maldonado}

Privilegios episcopales: la inviolabilidad de los obispos visigóticos y el delito de lesa majestad

\section{MÁxIMO DIAGO HERNANDO}

Alonso de Fonseca, Obispo de Ávila, Cuenca y Osma, y el ascenso de un linaje de exiliados portugueses en la Castilla de los siglos XV y XVI

\section{Antonio PIO dI Cosmo}

Santa Brigida ed il Monte Gargano: un paesaggio dell'anima. La descrizione dell'ambiente come stratagemma d'ammaestramento morale

\section{FERRAN ESQUILACHE}

La 'fila' de agua valenciana y otras medidas de aforo. La verdadera naturaleza de un sistema de medición de caudales de origen andalusí

\section{Alejandro Esteban Álvarez}

Habices del Reino de Granada averiguados en 1528 y 1531: la țā'a nazarí de Órgiva (Alpujarra)

\section{JaVier Gómez Gómez \& IÑAKı MARTín VISO}

Rationes y decimas: evidencias sobre la gestión de las sernas en el siglo XI en el noroeste de la Península Ibérica
383 SANTIAGO GONZÁLEZ SÁNCHEZ

Aportaciones de Paredes de Nava a las campañas militares de Infante Don Fernando, señor de la villa y regente de Castilla, contra el Reino Nazarí de Granada en 1407 y en 1410

429 ANTONI LLIBRER ESCRIG

Una máquina para la industria medieval. Los batanes del sur valenciano: integración y negocio. Nuevas aportaciones (1490-1502)

455 José Miguel López Villalba Comunicación escrita y oral de la ordenanza municipa (siglos XV-XVI)

501 Emilio Martín Gutiérrez

El aprovechamiento de los recursos naturales: la grana en Andalucía occidental durante el siglo XV

\section{Volumen II}

537 VERA-CRuz Miranda MENACHO

$(1421-1461)$

Las finanzas de un heredero: Carlos de Aragón y Navarra

569 Raúl Morales Muñoz

Hacia una revalorización del conciliarismo hispano bajomedieval: el Defensorium Trium Conclusionum de Alfonso de Madrigal

605 David Nogales Rincón

Enrique III de Castilla (1390-1406) y la indagación de rentas: un proyecto regio para la búsqueda de mineros y tesoros a inicios de cuatrocientos

6.7.7 Gonzalo Oliva Manso

Seisenes y novenes. Tiempos de calma para la moneda castellano-leonesa (1282-1312)

685 Alberto Peña Fernández y Manuel García Alonso Una inscripción medieval inédita en la iglesia de San Miguel de Aguayo (Cantabria)

713 RODRIGO POUSA DIÉGUEZ

Configuración institucional de una villa costera: Muros en el tránsito de la Edad Media a la Edad Moderna

\subsection{JuAn A. Prieto Sayagués}

Las profesiones femeninas de la nobleza y de las oligarquías urbanas en la Castilla bajomedieval. Causas, dinámicas, privilegios y donaciones 


\section{4}

\section{ESPACIO,}

\section{TIEMPO}

Y FORMA

UกED

SERIE III HISTORIA MEDIEVAL

REVISTA DE LA FACULTAD DE GEOGRAFÍA E HISTORIA

815 María del Pilar Rábade Obradó

El miedo a la Inquisición en la Castilla de los Reyes Católicos

84.5 Carlos Manuel Reglero de la Fuente

EL abad contra el rey (y los regidores): conflicto de jurisdicciones y ejercicio del poder en Sahagún (1398-1417)

881 Manuel Alejandro Rodríguez de la Peña

Eusebius and Alcuin on Constantine and Charlemagne as Wise Rulers: Sapiential Rulership in Late Antiquity and the Early Middle Ages

9)15 Antonio SÁnCHEZ GonzÁlez

El Archivo de los Mariscales de Castilla y Marqueses de Malagón

\section{Estudios y comentarios}

9. 51 Serafín Olcoz Yanguas

Apostilla al estudio Influencia de las redes nobiliarias en la expansión cristiana del siglo XII: el caso de Soria (ETF, 33, 2020)

\section{Libros · Books}

969 CAstrillo CASAdo, Janire, Las mujeres vascas durante la Baja Edad Media (MARía Jesús Fuente)

973 Crónica del rey Juan II de Castilla. Minoría y primeros años de reinado (1406-1420) GARCIA, Michel (edición y estudio) (VÍctor MUÑ̃z GómEZ)

981 DA Silva, Marcelo Cândido, História Medieval (DIEgo CARLo AMÉNDOLLA SPÍNOLA)

9.87 Galende Díaz, Juan Carlos y Ávila SeoAne, Nicolás, El rodado regio hispánico. Fernando III de León y Castilla (12301252) (MAURICIO HERRERO JIMÉNEZ)

989 García IzQuierdo, Iván, Frontera, fuero y concejos. EI valle del Riaza en la Edad Media (siglos VIII-XII) (CARLOS BARQUERO GOÑI)

993 García IzQuierdo, Iván y Peterson, David (coords.), Camino y Señorío. Obra selecta de Luis Martínez García (ENRIQUe CANTERA MONTENEgRO)

995 GonzÁlez PAz, Carlos Andrés, O Bispado de Mondoñedo na Idade Media. Territorio, comunidade e poder (ENRIQUE CANTERA Montenegro) 


\section{4}

\section{ESPACIO,}

\section{TIEMPO}

Y FORMA

UกED

SERIE III HISTORIA MEDIEVAL

REVISTA DE LA FACULTAD DE GEOGRAFİA E HISTORIA

\section{Libros · Books}

9) López MARtínez, Amalia, Minutarios notariales de Estevo Pérez (Ourense, siglo XIV) (José MIgUel LóPEz VILLALBA)

999 Miranda García, Fermín y López de Guereño SAnz, María Teresa (eds.), La muerte de los príncipes en la Edad Media. Balance y perspectivas historiográficas (ANA ECHEVARRÍA ARSUAGA)

1003 Motis Dolader, Miguel Ángel, Vivencias, emocionesy perfiles femeninos. Judeoconversas e Inquisición en Aragón en el siglo XV (ANA ECHEVARría ARsuaga)

1007 Solórzano Telechea, Jesús Ángel y Martín PÉrez, Fernando (coords.), Rutas de comunicación marítima y terrestre en los reinos hispánicos durante la Baja Edad Media. Movilidad, conectividad y gobernanza (ENRIQUE JOSÉ RUIZ PILARES)

1013 TORRE, Sandra de la - ETXEBERRIA, Ekaitz - DíAz DE DURANA, José Ramón (coords.), Valer más en la tierra. Poder, violencia y linaje en el País Vasco bajomedieval (ENRIQUE CANTERA MONTENEGRO)

1015 TRILlo SAN José, Carmen, La Vega de Granada a partir de documentación árabe romanceada inédita (1457-1494). Estudio, edición e índices (INMACULADA GONZÁLEZ SOPEÑA)

1019 Val Valdivieso, M. ${ }^{a}$ Isabel - VillanueVa ZubizarReta, Olatz (Coords.), Pero Ansúrez. El conde, su época y su memoria (ENRIQUe CANTERA MONTENEGRO)

1021 Villanueva Morte, Concepción y Fernández de Córdova Miralles, Álvaro, El embajador Claver. Diplomacia y conflicto en las «Guerras de Italia» (1495-1504) (ENRIQUE Cantera Montenegro) 